Supplementary Data Set 1:

\title{
Functional and Structural Analysis of a novel acyltransferase from pathogenic Phytophthora melonis
}

Aqeel Ahmad ${ }^{1}$, Waheed Akram ${ }^{1}$, Zoobia Bashir ${ }^{2}$, Iqra Shahzadi ${ }^{3}$, Rui Wang ${ }^{1}$, Hafiz

Muhammad Khalid Abbas ${ }^{1}$, Du Hu ${ }^{1}$, Shakeel Ahmed ${ }^{4}$, Xiaomei Xu ${ }^{1}$, Guihua Li ${ }^{1}$, Tingquan $\mathrm{Wu}^{1, *}$

${ }^{1}$ Vegetable Research Institute, Guangdong Academy of Agricultural Sciences / Guangdong Key Laboratory for New Technology Research of Vegetables, Guangzhou-510640, China

${ }^{2}$ National Laboratory of Solid State Microstructures, Department of Physics, Nanjing University, 22 Hankou Road, Nanjing, Jiangsu 210093, P.R. China.

${ }^{3}$ School of Resource and Environmental Science, Wuhan University, Wuhan 430072, Hubei, China.

${ }^{4}$ Instituto de Farmacia, Facultad de Ciencias, Universidad Austral de Chile, Campus Isla Teja, Valdivia 5090000, Chile

*Corresponding author: Tingquan WuＥmail: tingquanwu@sina.com

Address: Guangdong Key Laboratory for New Technology Research of Vegetables, Vegetable Research Institute, Guangdong Academy of Agricultural Sciences, Guangzhou, 510640, China. 
Supplementary Data Set 1:

Table S1: A list of peptide repeats along with their functions and publically available accessions.

\begin{tabular}{|c|c|c|c|}
\hline ACCESSION & NAME & $\begin{array}{l}\text { INTEGRATED } \\
\text { SIGNATURE(S) }\end{array}$ & FEATURES \\
\hline IPR000033 & LDLR class B repeat & $\begin{array}{l}\text { SM00135 } \\
\text { PF00058 } \\
\text { PS51120 } \\
\end{array}$ & \\
\hline IPR000102 & Neuraxin/MAP1B repeat & $\begin{array}{l}\text { PS00230 } \\
\text { PF00414 }\end{array}$ & \\
\hline IPR000225 & Armadillo & $\begin{array}{l}\text { SM00185 } \\
\text { PF00514 } \\
\text { PS50176 }\end{array}$ & protein binding \\
\hline IPR000258 & Bacterial ice-nucleation, octamer repeat & $\begin{array}{l}\text { PF00818 } \\
\text { PR00327 } \\
\text { PS00314 } \\
\end{array}$ & $\begin{array}{l}\text { cell outer } \\
\text { membrane }\end{array}$ \\
\hline IPR000354 & Involucrin repeat & PF00904 & $\begin{array}{l}\text { keratinization } \\
\text { cytoplasm }\end{array}$ \\
\hline IPR000357 & HEAT repeat & PF02985 & protein binding \\
\hline IPR000408 & $\begin{array}{l}\text { Regulator of chromosome condensation, } \\
\text { RCC1 }\end{array}$ & $\begin{array}{l}\text { PF00415 } \\
\text { PR00633 } \\
\text { PS00625 } \\
\text { PS00626 } \\
\text { PS50012 } \\
\end{array}$ & \\
\hline IPR000420 & Yeast PIR protein repeat & $\begin{array}{l}\text { PF00399 } \\
\text { PS00929 } \\
\text { PS50256 }\end{array}$ & $\begin{array}{l}\text { structural } \\
\text { constituent of cell } \\
\text { wall } \\
\text { cell wall }\end{array}$ \\
\hline IPR000479 & $\begin{array}{l}\text { Cation-independent mannose-6- } \\
\text { phosphate receptor repeat }\end{array}$ & PF00878 & $\begin{array}{l}\text { lysosomal } \\
\text { transport } \\
\text { insulin-like } \\
\text { growth factor } \\
\text { binding } \\
\text { mannose binding } \\
\text { signaling receptor } \\
\text { activity }\end{array}$ \\
\hline IPR000547 & Clathrin, heavy chain/VPS, 7-fold repeat & $\begin{array}{l}\text { SM00299 } \\
\text { PF00637 } \\
\text { PS50236 }\end{array}$ & $\begin{array}{l}\text { intracellular } \\
\text { protein transport } \\
\text { vesicle-mediated } \\
\text { transport }\end{array}$ \\
\hline IPR000557 & Calponin repeat & $\begin{array}{l}\text { PF00402 } \\
\text { PS51122 } \\
\text { PS01052 }\end{array}$ & \\
\hline IPR000607 & $\begin{array}{l}\text { Double-stranded RNA-specific } \\
\text { adenosine deaminase (DRADA) repeat }\end{array}$ & PS50139 & $\begin{array}{l}\text { RNA binding } \\
\text { double-stranded } \\
\text { RNA adenosine }\end{array}$ \\
\hline
\end{tabular}


Supplementary Data Set 1:

\begin{tabular}{|c|c|c|c|}
\hline & & & $\begin{array}{l}\text { deaminase } \\
\text { activity }\end{array}$ \\
\hline IPR000684 & $\begin{array}{l}\text { RNA polymerase II, heptapeptide repeat, } \\
\text { eukaryotic }\end{array}$ & $\begin{array}{l}\text { PF05001 } \\
\text { PS00115 }\end{array}$ & $\begin{array}{l}\text { transcription by } \\
\text { RNA polymerase } \\
\text { II } \\
\text { DNA binding } \\
\text { RNA polymerase } \\
\text { II, core complex }\end{array}$ \\
\hline IPR000884 & Thrombospondin type-1 (TSP1) repeat & $\begin{array}{l}\text { PF00090 } \\
\text { SM00209 } \\
\text { PS50092 }\end{array}$ & \\
\hline IPR000900 & Nebulin repeat & $\begin{array}{l}\text { PF00880 } \\
\text { SM00227 } \\
\text { PS51216 }\end{array}$ & \\
\hline IPR000939 & $\begin{array}{l}\text { Adenoviral fibre protein, repeat/shaft } \\
\text { region }\end{array}$ & PF00608 & $\begin{array}{l}\text { virion attachment } \\
\text { to host cell }\end{array}$ \\
\hline IPR001084 & $\begin{array}{l}\text { Microtubule associated protein, tubulin- } \\
\text { binding repeat }\end{array}$ & $\begin{array}{l}\text { PF00418 } \\
\text { PS00229 } \\
\text { PS51491 } \\
\end{array}$ & tubulin binding \\
\hline IPR001101 & Plectin repeat & $\begin{array}{l}\text { SM00250 } \\
\text { PF00681 }\end{array}$ & cytoskeleton \\
\hline IPR001258 & NHL repeat & PF01436 & protein binding \\
\hline IPR001259 & Proteinase inhibitor I27, calpastatin & PF00748 & \\
\hline IPR001298 & Filamin/ABP280 repeat & SM00557 & protein binding \\
\hline IPR001313 & Pumilio RNA-binding repeat & $\begin{array}{l}\text { SM00025 } \\
\text { PF00806 } \\
\text { PS50302 }\end{array}$ & RNA binding \\
\hline IPR001330 & PFTB repeat & PF00432 & catalytic activity \\
\hline IPR001343 & $\begin{array}{l}\text { RTX calcium-binding nonapeptide } \\
\text { repeat }\end{array}$ & PF00353 & $\begin{array}{l}\text { calcium ion } \\
\text { binding }\end{array}$ \\
\hline IPR001370 & BIR repeat & $\begin{array}{l}\text { SM00238 } \\
\text { PF00653 } \\
\text { PS01282 } \\
\text { PS50143 } \\
\text { cd00022 }\end{array}$ & \\
\hline IPR001389 & Flocculin & PF00624 & flocculation \\
\hline IPR001440 & Tetratricopeptide repeat 1 & PF00515 & protein binding \\
\hline IPR001443 & Staphylocoagulase repeat & $\begin{array}{l}\text { PF04022 } \\
\text { PS00429 }\end{array}$ & \\
\hline IPR001451 & Hexapeptide repeat & $\begin{array}{l}\text { PF00132 } \\
\text { PF14602 }\end{array}$ & \\
\hline IPR001610 & PAC motif & SM00086 & \\
\hline IPR001611 & Leucine-rich repeat & $\begin{array}{l}\text { PS51450 } \\
\text { PF00560 } \\
\text { PF13516 } \\
\text { PF13855 }\end{array}$ & protein binding \\
\hline
\end{tabular}


Supplementary Data Set 1:

\begin{tabular}{|c|c|c|c|}
\hline IPR001646 & Pentapeptide repeat & $\begin{array}{l}\text { PF00805 } \\
\text { PF13576 } \\
\text { PF13599 } \\
\end{array}$ & \\
\hline IPR001673 & Dictyostelium (slime mold) repeat & PF00526 & \\
\hline IPR001680 & WD40 repeat & $\begin{array}{l}\text { PF00400 } \\
\text { SM00320 } \\
\text { PS50082 } \\
\end{array}$ & protein binding \\
\hline IPR001893 & $\begin{array}{l}\text { Cysteine-rich Golgi apparatus protein } 1 \\
\text { repeat }\end{array}$ & PF00839 & membrane \\
\hline IPR002003 & Gas vesicle protein GvpC & $\begin{array}{l}\text { TIGR02641 } \\
\text { PF01304 }\end{array}$ & $\begin{array}{l}\text { gas vesicle } \\
\text { organization } \\
\text { gas vesicle }\end{array}$ \\
\hline IPR002015 & Proteasome/cyclosome repeat & PF01851 & \\
\hline IPR002017 & Spectrin repeat & PF00435 & protein binding \\
\hline IPR002088 & Protein prenyltransferase, alpha subunit & $\begin{array}{l}\text { PF01239 } \\
\text { PS51147 }\end{array}$ & $\begin{array}{l}\text { protein } \\
\text { prenylation } \\
\text { protein } \\
\text { prenyltransferase } \\
\text { activity }\end{array}$ \\
\hline IPR002093 & BRCA2 repeat & $\begin{array}{l}\text { PF00634 } \\
\text { PS50138 }\end{array}$ & \\
\hline IPR002098 & Seminal vesicle protein I & PS00313 & $\begin{array}{l}\text { copulation } \\
\text { extracellular } \\
\text { region }\end{array}$ \\
\hline IPR002105 & Dockerin type I repeat & $\begin{array}{l}\text { PF00404 } \\
\text { PS00448 }\end{array}$ & $\begin{array}{l}\text { polysaccharide } \\
\text { catabolic process } \\
\text { hydrolase } \\
\text { activity, } \\
\text { hydrolyzing O- } \\
\text { glycosyl } \\
\text { compounds }\end{array}$ \\
\hline IPR002110 & Ankyrin repeat & $\begin{array}{l}\text { SM00248 } \\
\text { PF00023 } \\
\text { PF13606 } \\
\text { PS50088 } \\
\text { PR01415 }\end{array}$ & protein binding \\
\hline IPR002134 & Histidine-rich calcium-binding repeat & PS00328 & \\
\hline IPR002165 & Plexin repeat & PF01437 & \\
\hline IPR002172 & $\begin{array}{l}\text { Low-density lipoprotein (LDL) receptor } \\
\text { class A repeat }\end{array}$ & $\begin{array}{l}\text { PF00057 } \\
\text { SM00192 } \\
\text { PR00261 } \\
\text { cd00112 } \\
\text { PS50068 } \\
\end{array}$ & protein binding \\
\hline IPR002372 & Pyrrolo-quinoline quinone repeat & $\begin{array}{l}\text { PF01011 } \\
\text { PF13360 } \\
\end{array}$ & \\
\hline IPR002499 & Major vault protein, N-terminal & PS51224 & \\
\hline
\end{tabular}


Supplementary Data Set 1:

\begin{tabular}{|c|c|c|c|}
\hline IPR002515 & Zinc finger, C2H2C-type & $\begin{array}{l}\text { PF01530 } \\
\text { PS51802 }\end{array}$ & $\begin{array}{l}\text { regulation of } \\
\text { transcription, } \\
\text { DNA-templated } \\
\text { DNA-binding } \\
\text { transcription } \\
\text { factor activity } \\
\text { zinc ion binding } \\
\text { nucleus }\end{array}$ \\
\hline IPR002603 & ET repeat & PF01684 & \\
\hline IPR002860 & BNR repeat & $\begin{array}{l}\text { PF02012 } \\
\text { PF15899 }\end{array}$ & \\
\hline IPR002885 & Pentatricopeptide repeat & $\begin{array}{l}\text { TIGR00756 } \\
\text { PF01535 } \\
\text { PF13812 } \\
\text { PF13041 } \\
\text { PF12854 } \\
\text { PS51375 } \\
\end{array}$ & \\
\hline IPR002895 & Paramecium surface antigen & $\begin{array}{l}\text { SM00639 } \\
\text { PF01508 }\end{array}$ & \\
\hline IPR002989 & Mycobacterial pentapeptide repeat & PF01469 & \\
\hline IPR003107 & HAT (Half-A-TPR) repeat & $\begin{array}{l}\text { SM00386 } \\
\text { PF02184 }\end{array}$ & RNA processing \\
\hline IPR003110 & $\begin{array}{l}\text { Phosphorylated immunoreceptor } \\
\text { signalling ITAM }\end{array}$ & $\begin{array}{l}\text { PF02189 } \\
\text { SM00077 } \\
\text { PS51055 }\end{array}$ & $\begin{array}{l}\text { cell surface } \\
\text { receptor signaling } \\
\text { pathway } \\
\text { transmembrane } \\
\text { signaling receptor } \\
\text { activity } \\
\text { membrane }\end{array}$ \\
\hline IPR003134 & Hs1/Cortactin & $\begin{array}{l}\text { PF02218 } \\
\text { PS51090 }\end{array}$ & \\
\hline IPR003147 & Protein L, Ig light chain-binding & PF02246 & \\
\hline IPR003341 & Cysteine rich repeat, tripleX & PF02363 & \\
\hline IPR003345 & M protein repeat & PF02370 & \\
\hline IPR003367 & Thrombospondin, type 3-like repeat & PF02412 & $\begin{array}{l}\text { cell adhesion } \\
\text { calcium ion } \\
\text { binding }\end{array}$ \\
\hline IPR003368 & $\begin{array}{l}\text { Polymorphic outer membrane protein } \\
\text { repeat }\end{array}$ & $\begin{array}{l}\text { TIGR01376 } \\
\text { PF02415 }\end{array}$ & \\
\hline IPR003409 & MORN motif & $\begin{array}{l}\text { SM00698 } \\
\text { PF02493 }\end{array}$ & \\
\hline IPR003460 & Insect antifreeze protein motif & PF02420 & \\
\hline IPR003591 & Leucine-rich repeat, typical subtype & SM00369 & \\
\hline IPR003647 & Intron encoded nuclease repeat & SM00497 & \\
\hline IPR003681 & Glycophorin-binding protein & $\begin{array}{l}\text { PS51069 } \\
\text { PF02526 }\end{array}$ & \\
\hline
\end{tabular}


Supplementary Data Set 1:

\begin{tabular}{|c|c|c|c|}
\hline IPR003822 & Paired amphipathic helix & $\begin{array}{l}\text { PS5 } 1477 \\
\text { PF02671 }\end{array}$ & $\begin{array}{l}\text { regulation of } \\
\text { transcription, } \\
\text { DNA-templated }\end{array}$ \\
\hline IPR003883 & $\begin{array}{l}\text { Repetitive proline-rich cell wall protein } \\
\text { repeat }\end{array}$ & PF02095 & $\begin{array}{l}\text { structural } \\
\text { constituent of cell } \\
\text { wall }\end{array}$ \\
\hline IPR003900 & KID repeat & PF02524 & \\
\hline IPR004018 & RPEL repeat & $\begin{array}{l}\text { SM00707 } \\
\text { PF02755 } \\
\text { PS51073 } \\
\end{array}$ & \\
\hline IPR004092 & Mbt repeat & $\begin{array}{l}\text { SM00561 } \\
\text { PF02820 } \\
\text { PS51079 }\end{array}$ & $\begin{array}{l}\text { regulation of } \\
\text { transcription, } \\
\text { DNA-templated } \\
\text { nucleus }\end{array}$ \\
\hline IPR004153 & CXCXC repeat & PF03128 & \\
\hline IPR004155 & PBS lyase HEAT-like repeat & $\begin{array}{l}\text { SM00567 } \\
\text { PF03130 }\end{array}$ & \\
\hline IPR004168 & PPAK motif & PF02818 & \\
\hline IPR004212 & GTF2I-like repeat & $\begin{array}{l}\text { PF02946 } \\
\text { PS51139 }\end{array}$ & \\
\hline IPR004237 & Fibronectin binding repeat & PF02986 & \\
\hline IPR004296 & DUF236 repeat & PF03057 & \\
\hline IPR004828 & Apidaecin & PF00807 & \\
\hline IPR004830 & Leucine rich repeat variant & PF01816 & \\
\hline IPR004874 & Borrelia repeat protein & PF03183 & \\
\hline IPR005003 & $\begin{array}{l}\text { Bacteriophage lambda, Stf, side tail } \\
\text { fibre-repeat-1 }\end{array}$ & PF03335 & $\begin{array}{l}\text { structural } \\
\text { molecule activity }\end{array}$ \\
\hline IPR005038 & Octapeptide repeat & PF03373 & $\begin{array}{l}\text { immunoglobulin } \\
\text { binding }\end{array}$ \\
\hline IPR005042 & TAL effector repeat & PF03377 & \\
\hline IPR005068 & $\begin{array}{l}\text { Bacteriophage lambda, Stf, side tail } \\
\text { fibre-repeat-2 }\end{array}$ & PF03406 & \\
\hline IPR005213 & HGWP repeat & PF03578 & \\
\hline IPR005297 & Lipoprotein repeat & PF03640 & \\
\hline IPR005325 & $\begin{array}{l}\text { Protein of unknown function DUF308, } \\
\text { membrane }\end{array}$ & PF03729 & \\
\hline IPR005328 & Sic protein repeat & PF03482 & \\
\hline IPR005492 & $\begin{array}{l}\text { Leucine-rich glioma-inactivated, EPTP } \\
\text { repeat }\end{array}$ & PF03736 & \\
\hline IPR005506 & Protein of unknown function DUF312 & PF03752 & \\
\hline IPR005529 & Protein of unknown function DUF321 & PF03778 & \\
\hline IPR005530 & SPW repeat & PF03779 & \\
\hline IPR005560 & Protein of unknown function DUF326 & PF03860 & \\
\hline IPR006031 & XYPPX repeat & PF02162 & \\
\hline IPR006150 & Cysteine-rich repeat & SM00289 & \\
\hline
\end{tabular}


Supplementary Data Set 1:

\begin{tabular}{|c|c|c|c|}
\hline IPR006212 & Furin-like repeat & $\begin{array}{l}\text { SM00261 } \\
\text { PF15913 } \\
\text { cd00064 }\end{array}$ & \\
\hline IPR006270 & Streptococcal histidine triad repeat & PF04270 & \\
\hline IPR006489 & Plasmodium yoelii repeat of length 46 & $\begin{array}{l}\text { TIGR01602 } \\
\text { PF09689 }\end{array}$ & \\
\hline IPR006530 & YD repeat & TIGR01643 & \\
\hline IPR013211 & LVIVD & PF08309 & \\
\hline IPR013378 & Listeria/Bacterioides repeat & $\begin{array}{l}\text { TIGR02543 } \\
\text { PF09479 }\end{array}$ & \\
\hline IPR013425 & $\begin{array}{l}\text { Autotransporter-associated beta strand } \\
\text { repeat }\end{array}$ & $\begin{array}{l}\text { TIGR02601 } \\
\text { PF12951 }\end{array}$ & \\
\hline IPR013431 & Delta-60 repeat & $\begin{array}{l}\text { TIGR02608 } \\
\text { PF17164 }\end{array}$ & \\
\hline IPR013517 & FG-GAP repeat & $\begin{array}{l}\text { PF01839 } \\
\text { PF14312 }\end{array}$ & \\
\hline IPR013519 & Integrin alpha beta-propellor & $\begin{array}{l}\text { PS51470 } \\
\text { SM00191 }\end{array}$ & \\
\hline IPR013688 & GBS Bsp-like & PF08481 & \\
\hline IPR014003 & DM16 repeat & SM00683 & \\
\hline IPR014262 & Extracellular HAF & TIGR02913 & \\
\hline IPR015129 & Titin, $\mathrm{Z}$ repeat & PF09042 & \\
\hline IPR015792 & Kinesin light chain repeat & PS01160 & \\
\hline IPR017845 & Chlorosome envelope protein $\mathrm{H}, \mathrm{CsmH}$ & TIGR03058 & \\
\hline IPR017868 & Filamin/ABP280 repeat-like & $\begin{array}{l}\text { PF00630 } \\
\text { PS50194 }\end{array}$ & \\
\hline IPR017873 & $\begin{array}{l}\text { Cysteine-rich Golgi apparatus protein } 1 \\
\text { repeat, eukaryote }\end{array}$ & PS51289 & Golgi membrane \\
\hline IPR017897 & Thrombospondin, type 3 repeat & PS51234 & \\
\hline IPR018108 & Mitochondrial substrate/solute carrier & $\begin{array}{l}\text { PF00153 } \\
\text { PS50920 }\end{array}$ & \\
\hline IPR018159 & Spectrin/alpha-actinin & SM00150 & \\
\hline IPR018185 & Gas vesicle $\mathrm{C}$ repeat & PS00235 & \\
\hline IPR018337 & Cell wall/choline-binding repeat & $\begin{array}{l}\text { PF01473 } \\
\text { PS51170 }\end{array}$ & \\
\hline IPR018391 & $\begin{array}{l}\text { Pyrrolo-quinoline quinone beta-propeller } \\
\text { repeat }\end{array}$ & SM00564 & \\
\hline IPR018487 & Hemopexin-like repeats & $\begin{array}{l}\text { SM00120 } \\
\text { PF00045 } \\
\text { PS51642 } \\
\end{array}$ & \\
\hline IPR018502 & Annexin repeat & $\begin{array}{l}\text { SM00335 } \\
\text { PF00191 }\end{array}$ & $\begin{array}{l}\text { calcium ion } \\
\text { binding } \\
\text { calcium- } \\
\text { dependent }\end{array}$ \\
\hline
\end{tabular}


Supplementary Data Set 1:

\begin{tabular}{|c|c|c|c|}
\hline & & & $\begin{array}{l}\text { phospholipid } \\
\text { binding }\end{array}$ \\
\hline IPR018803 & Putative stress-responsive protein & PF10281 & \\
\hline IPR018942 & Seminal vesicle protein repeat & PF10578 & \\
\hline IPR018975 & Pseudomurein-binding repeat & PF09373 & \\
\hline IPR019541 & $\begin{array}{l}\text { Trappin protein transglutaminase- } \\
\text { binding repeat }\end{array}$ & PF10511 & \\
\hline IPR019552 & Histidine-rich calcium-binding & PF10529 & \\
\hline IPR019562 & $\begin{array}{l}\text { Micronemal adhesive repeat, sialic-acid } \\
\text { binding }\end{array}$ & PF10564 & \\
\hline IPR019626 & Stress-induced protein, KGG, repeat & PF10685 & \\
\hline IPR019734 & Tetratricopeptide repeat & $\begin{array}{l}\text { SM00028 } \\
\text { PS50005 } \\
\text { PF13176 } \\
\text { PF13181 } \\
\text { PF13174 }\end{array}$ & protein binding \\
\hline IPR020472 & G-protein beta WD-40 repeat & PR00320 & \\
\hline IPR020949 & Prion, copper binding octapeptide repeat & PF03991 & \\
\hline IPR021021 & Fibronectin-binding repeat, SSURE & PF11966 & \\
\hline IPR021133 & HEAT, type 2 & PS50077 & \\
\hline IPR021655 & Putative metal-binding motif & PF11617 & \\
\hline IPR021839 & $\begin{array}{l}\text { Early growth response protein } 1, \mathrm{C}- \\
\text { terminal }\end{array}$ & PF11914 & \\
\hline IPR021984 & Plasmodium repeat & PF12135 & \\
\hline IPR022365 & Clathrin, heavy chain, propeller repeat & PF01394 & \\
\hline IPR022435 & Surface-anchored repeat, actinobacteria & TIGR03769 & \\
\hline IPR022441 & Parallel beta-helix repeat-2 & TIGR03804 & \\
\hline IPR022444 & Cofactor-binding repeat, putative & TIGR03807 & \\
\hline IPR022519 & Gloeobacter/Verrucomicrobia repeat & TIGR03803 & \\
\hline IPR023908 & xxxLxxG heptad repeat & TIGR03057 & \\
\hline IPR024446 & PXPV repeat & PF12778 & \\
\hline IPR024447 & YXWGXW repeat & PF12779 & \\
\hline IPR024613 & Huntingtin, middle-repeat & PF12372 & \\
\hline IPR025157 & Hemagglutinin repeat & PF13332 & \\
\hline IPR025527 & HUWE1/Rev1, ubiquitin binding region & PF14377 & \\
\hline IPR025574 & Nucleoporin FG repeat & PF13634 & \\
\hline IPR025589 & Topoisomerase C-terminal repeat & $\begin{array}{l}\text { PF13368 } \\
\text { PF13342 } \\
\end{array}$ & \\
\hline IPR025667 & SprB repeat & PF13573 & \\
\hline IPR025875 & Leucine rich repeat 4 & PF12799 & \\
\hline IPR025900 & Nuclear receptor repeat & PF14046 & \\
\hline IPR025928 & Flocculin type 3 repeat & PF13928 & \\
\hline IPR026003 & $\begin{array}{l}\text { HEAT repeat associated with sister } \\
\text { chromatid cohesion protein }\end{array}$ & PF12765 & \\
\hline IPR026393 & Modification target Cys-rich repeat & TIGR04114 & \\
\hline
\end{tabular}


Supplementary Data Set 1:

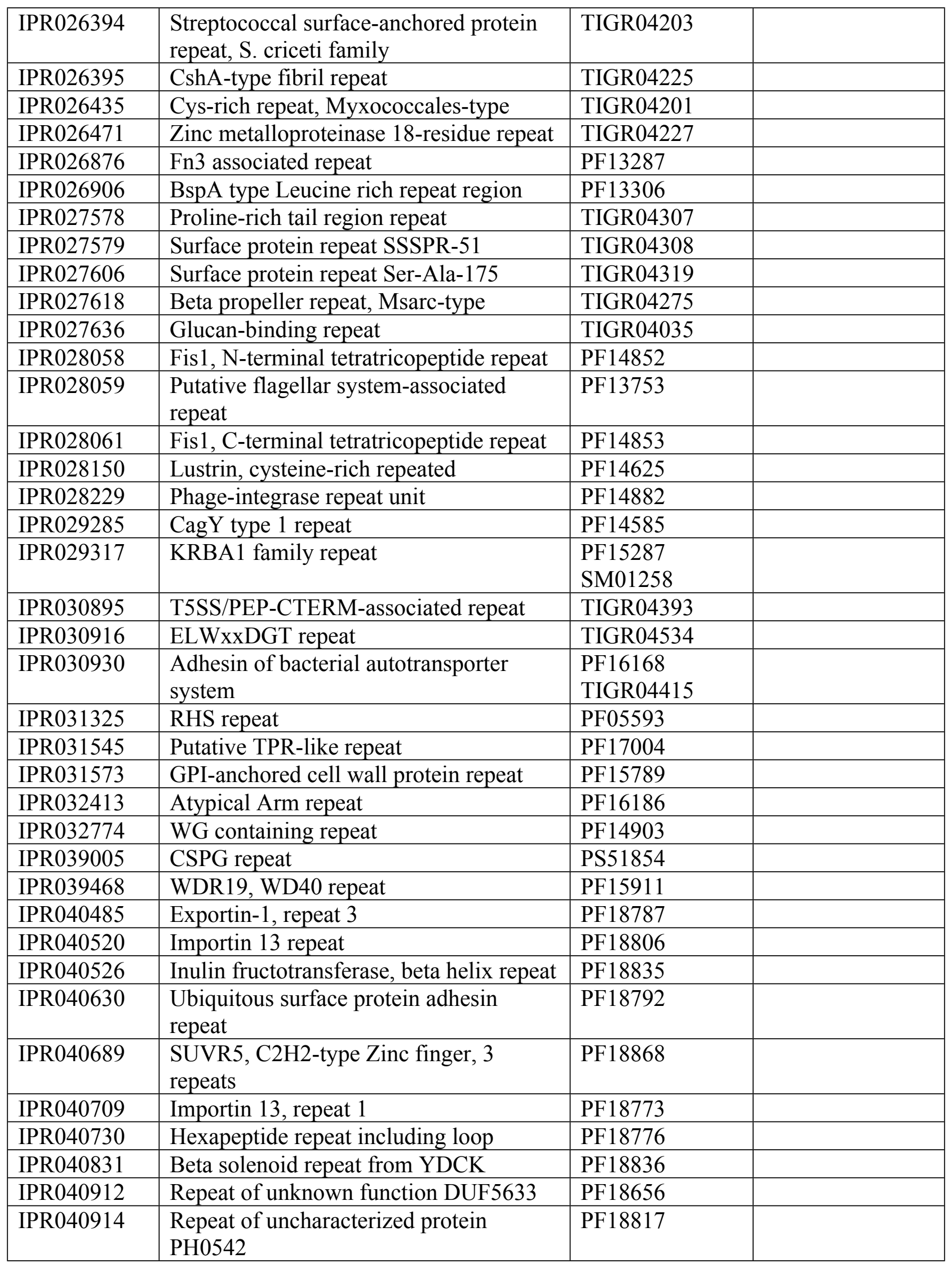


Supplementary Data Set 1:

\begin{tabular}{|l|l|l|l|}
\hline IPR040928 & Importin repeat & PF18816 & \\
\hline IPR040931 & Cadmium carbonic anhydrase repeat & PF18484 & \\
\hline IPR040944 & Importin 13 repeat 2 & PF18786 & \\
\hline IPR040962 & Tetratricopeptide-like repeat & PF18833 & \\
\hline IPR040972 & Alstrom syndrome repeat & PF18727 & \\
\hline IPR041025 & Homing endonuclease repeat & PF18780 & \\
\hline IPR041114 & $\begin{array}{l}\text { Nitrous oxide reductase, propeller repeat } \\
\text { 1 }\end{array}$ & PF18764 & \\
\hline IPR041123 & Chromosome region maintenance repeat & PF18777 & \\
\hline IPR041142 & $\begin{array}{l}\text { Nitrous oxide reductase, propeller repeat } \\
2\end{array}$ & PF18793 & \\
\hline IPR041209 & $\begin{array}{l}\text { Vesicle tethering protein p115, armadillo } \\
\text { tether-repeat }\end{array}$ & PF18770 & \\
\hline IPR041235 & Exportin-1, repeat 2 & PF18784 & \\
\hline IPR041257 & $\begin{array}{l}\text { Adenomatous polyposis coli (APC) } \\
\text { repeat }\end{array}$ & PF18797 & \\
\hline IPR041274 & Isopullulanase beta-solenoid repeat & PF18783 & \\
\hline IPR041281 & CD180, leucine-rich repeat & PF18831 & \\
\hline IPR041283 & Leucine-rich repeat unit & PF18837 & \\
\hline IPR041302 & $\begin{array}{l}\text { Ribonuclease inhibitor, leucine rich } \\
\text { repeat cap }\end{array}$ & PF18779 & \\
\hline IPR041303 & Phage spike trimer 2 & PF18781 & \\
\hline IPR041315 & PlcR, tetratricopeptide repeat & PF18768 & \\
\hline IPR041389 & Importin repeat 6 & PF18829 & \\
\hline IPR041402 & Dextranase, beta solenoid repeat & PF18841 & \\
\hline IPR041403 & $\begin{array}{l}\text { DUF4458 domain-containing protein, } \\
\text { leucine-rich repeat }\end{array}$ & PF18805 & \\
\hline IPR041508 & Toxin complex C-like repeat & PF18807 & \\
\hline IPR041653 & Importin repeat 4 & \\
\hline
\end{tabular}


Supplementary Data Set 1:

Table S2: List of active sites in the protein H3GZF6.

\begin{tabular}{|c|c|c|c|}
\hline $\begin{array}{l}\text { ACCESSIO } \\
\mathrm{N}\end{array}$ & NAME & $\begin{array}{l}\text { INTEGRATED } \\
\text { SIGNATURE(S) }\end{array}$ & FEATURES \\
\hline IPR000126 & $\begin{array}{l}\text { Serine proteases, V8 family, serine } \\
\text { active site }\end{array}$ & PS00673 & $\begin{array}{l}\text { proteolysis } \\
\text { serine-type peptidase } \\
\text { activity }\end{array}$ \\
\hline IPR000138 & $\begin{array}{l}\text { Hydroxymethylglutaryl-CoA } \\
\text { lyase, active site }\end{array}$ & PS01062 & $\begin{array}{l}\text { hydroxymethylglutary } \\
\text { l-CoA lyase activity }\end{array}$ \\
\hline IPR000169 & $\begin{array}{l}\text { Cysteine peptidase, cysteine active } \\
\text { site }\end{array}$ & PS00139 & \\
\hline IPR000180 & Membrane dipeptidase, active site & PS00869 & $\begin{array}{l}\text { proteolysis } \\
\text { dipeptidase activity } \\
\text { dipeptidyl-peptidase } \\
\text { activity } \\
\text { metalloexopeptidase } \\
\text { activity }\end{array}$ \\
\hline IPR000189 & $\begin{array}{l}\text { Prokaryotic transglycosylase, } \\
\text { active site }\end{array}$ & PS00922 & $\begin{array}{l}\text { peptidoglycan } \\
\text { metabolic process } \\
\text { lytic transglycosylase } \\
\text { activity } \\
\text { membrane }\end{array}$ \\
\hline IPR000590 & $\begin{array}{l}\text { Hydroxymethylglutaryl-coenzyme } \\
\text { A synthase, active site }\end{array}$ & PS01226 & $\begin{array}{l}\text { isoprenoid } \\
\text { biosynthetic process } \\
\text { hydroxymethylglutary } \\
\text { 1-CoA synthase } \\
\text { activity }\end{array}$ \\
\hline IPR001252 & Malate dehydrogenase, active site & PS00068 & $\begin{array}{l}\text { malate metabolic } \\
\text { process } \\
\text { oxidation-reduction } \\
\text { process } \\
\text { malate dehydrogenase } \\
\text { activity }\end{array}$ \\
\hline IPR001345 & $\begin{array}{l}\text { Phosphoglycerate/bisphosphoglyce } \\
\text { rate mutase, active site }\end{array}$ & PS00175 & catalytic activity \\
\hline IPR001497 & $\begin{array}{l}\text { Methylated-DNA-[protein]- } \\
\text { cysteine S-methyltransferase, } \\
\text { active site }\end{array}$ & PS00374 & $\begin{array}{l}\text { DNA repair } \\
\text { methylated-DNA- } \\
\text { [protein]-cysteine S- } \\
\text { methyltransferase } \\
\text { activity }\end{array}$ \\
\hline IPR001555 & $\begin{array}{l}\text { Phosphoribosylglycinamide } \\
\text { formyltransferase, active site }\end{array}$ & PS00373 & \\
\hline IPR001579 & $\begin{array}{l}\text { Glycoside hydrolase, chitinase } \\
\text { active site }\end{array}$ & PS01095 & $\begin{array}{l}\text { carbohydrate } \\
\text { metabolic process } \\
\text { hydrolase activity, }\end{array}$ \\
\hline
\end{tabular}


Supplementary Data Set 1:

\begin{tabular}{|c|c|c|c|}
\hline & & & $\begin{array}{l}\text { hydrolyzing O- } \\
\text { glycosyl compounds }\end{array}$ \\
\hline IPR001586 & Beta-lactamase, class- $\mathrm{C}$ active site & PS00336 & $\begin{array}{l}\text { antibiotic catabolic } \\
\text { process } \\
\text { beta-lactamase activity } \\
\text { outer membrane- } \\
\text { bounded periplasmic } \\
\text { space }\end{array}$ \\
\hline IPR001969 & Aspartic peptidase, active site & PS00141 & $\begin{array}{l}\text { proteolysis } \\
\text { aspartic-type } \\
\text { endopeptidase activity }\end{array}$ \\
\hline IPR002071 & Thermonuclease active site & $\begin{array}{l}\text { PS01284 } \\
\text { PS01123 }\end{array}$ & $\begin{array}{l}\text { nuclease activity } \\
\text { nucleic acid binding }\end{array}$ \\
\hline IPR002137 & Beta-lactamase, class-D active site & PS00337 & $\begin{array}{l}\text { antibiotic catabolic } \\
\text { process } \\
\text { beta-lactamase activity }\end{array}$ \\
\hline IPR002168 & $\begin{array}{l}\text { Lipase, GDXG, putative histidine } \\
\text { active site }\end{array}$ & PS01173 & hydrolase activity \\
\hline IPR002471 & Peptidase S9, serine active site & PS00708 & $\begin{array}{l}\text { proteolysis } \\
\text { serine-type } \\
\text { endopeptidase activity }\end{array}$ \\
\hline IPR004164 & Coenzyme A transferase active site & PS01274 & $\begin{array}{l}\text { CoA-transferase } \\
\text { activity }\end{array}$ \\
\hline IPR006650 & $\begin{array}{l}\text { Adenosine/AMP deaminase active } \\
\text { site }\end{array}$ & PS00485 & $\begin{array}{l}\text { purine ribonucleoside } \\
\text { monophosphate } \\
\text { biosynthetic process } \\
\text { deaminase activity }\end{array}$ \\
\hline IPR008255 & $\begin{array}{l}\text { Pyridine nucleotide-disulphide } \\
\text { oxidoreductase, class-II, active site }\end{array}$ & PS00573 & $\begin{array}{l}\text { oxidation-reduction } \\
\text { process } \\
\text { oxidoreductase } \\
\text { activity }\end{array}$ \\
\hline IPR008259 & $\begin{array}{l}\text { FMN-dependent alpha-hydroxy } \\
\text { acid dehydrogenase, active site }\end{array}$ & PS00557 & $\begin{array}{l}\text { oxidation-reduction } \\
\text { process } \\
\text { oxidoreductase } \\
\text { activity }\end{array}$ \\
\hline IPR008261 & $\begin{array}{l}\text { Iodothyronine deiodinase, active } \\
\text { site }\end{array}$ & PS01205 & $\begin{array}{l}\text { oxidation-reduction } \\
\text { process } \\
\text { thyroxine } 5 \text { '- } \\
\text { deiodinase activity }\end{array}$ \\
\hline IPR008263 & $\begin{array}{l}\text { Glycoside hydrolase, family } 16, \\
\text { active site }\end{array}$ & PS01034 & $\begin{array}{l}\text { carbohydrate } \\
\text { metabolic process } \\
\text { hydrolase activity, } \\
\text { hydrolyzing O- } \\
\text { glycosyl compounds }\end{array}$ \\
\hline IPR008265 & Lipase, GDSL, active site & PS01098 & $\begin{array}{l}\text { lipid metabolic } \\
\text { process }\end{array}$ \\
\hline
\end{tabular}


Supplementary Data Set 1:

\begin{tabular}{|c|c|c|c|}
\hline & & & lipase activity \\
\hline IPR008266 & Tyrosine-protein kinase, active site & PS00109 & $\begin{array}{l}\text { protein } \\
\text { phosphorylation } \\
\text { protein kinase activity }\end{array}$ \\
\hline IPR008268 & Peptidase S16, active site & PS01046 & $\begin{array}{l}\text { proteolysis } \\
\text { ATP-dependent } \\
\text { peptidase activity } \\
\text { serine-type } \\
\text { endopeptidase activity }\end{array}$ \\
\hline IPR008270 & $\begin{array}{l}\text { Glycoside hydrolase, family } 25, \\
\text { active site }\end{array}$ & PS00953 & $\begin{array}{l}\text { cell wall } \\
\text { macromolecule } \\
\text { catabolic process } \\
\text { peptidoglycan } \\
\text { catabolic process } \\
\text { lysozyme activity }\end{array}$ \\
\hline IPR008271 & $\begin{array}{l}\text { Serine/threonine-protein kinase, } \\
\text { active site }\end{array}$ & PS00108 & $\begin{array}{l}\text { protein } \\
\text { phosphorylation } \\
\text { protein kinase activity }\end{array}$ \\
\hline IPR008272 & $\begin{array}{l}\text { 4-hydroxybenzoyl-CoA } \\
\text { thioesterase, active site }\end{array}$ & PS01328 & hydrolase activity \\
\hline IPR011767 & Glutaredoxin active site & PS00195 & $\begin{array}{l}\text { cell redox homeostasis } \\
\text { electron transfer } \\
\text { activity }\end{array}$ \\
\hline IPR012999 & $\begin{array}{l}\text { Pyridine nucleotide-disulphide } \\
\text { oxidoreductase, class I, active site }\end{array}$ & PS00076 & $\begin{array}{l}\text { oxidation-reduction } \\
\text { process } \\
\text { oxidoreductase } \\
\text { activity, acting on a } \\
\text { sulfur group of } \\
\text { donors, NAD(P) as } \\
\text { acceptor }\end{array}$ \\
\hline IPR013808 & Transglutaminase, active site & PS00547 & peptide cross-linking \\
\hline IPR016129 & $\begin{array}{l}\text { Peptidase family C14A, His active } \\
\text { site }\end{array}$ & PS01121 & \\
\hline IPR016130 & $\begin{array}{l}\text { Protein-tyrosine phosphatase, } \\
\text { active site }\end{array}$ & PS00383 & $\begin{array}{l}\text { dephosphorylation } \\
\text { protein tyrosine } \\
\text { phosphatase activity }\end{array}$ \\
\hline IPR017440 & $\begin{array}{l}\text { ATP-citrate lyase/succinyl-CoA } \\
\text { ligase, active site }\end{array}$ & PS00399 & \\
\hline IPR017950 & Urease active site & PS00145 & urease activity \\
\hline IPR018040 & Pectinesterase, Tyr active site & PS00800 & \\
\hline IPR018053 & $\begin{array}{l}\text { Glycoside hydrolase, family } 32, \\
\text { active site }\end{array}$ & PS00609 & $\begin{array}{l}\text { carbohydrate } \\
\text { metabolic process } \\
\text { hydrolase activity, } \\
\text { hydrolyzing O- } \\
\text { glycosyl compounds }\end{array}$ \\
\hline IPR018057 & Deoxyribonuclease I, active site & PS00919 & \\
\hline
\end{tabular}


Supplementary Data Set 1:

\begin{tabular}{|c|c|c|c|}
\hline IPR018085 & $\begin{array}{l}\text { Uracil-DNA glycosylase, active } \\
\text { site }\end{array}$ & PS00130 & $\begin{array}{l}\text { DNA repair } \\
\text { hydrolase activity, } \\
\text { hydrolyzing N- } \\
\text { glycosyl compounds }\end{array}$ \\
\hline IPR018088 & $\begin{array}{l}\text { Chalcone/stilbene synthase, active } \\
\text { site }\end{array}$ & PS00441 & $\begin{array}{l}\text { biosynthetic process } \\
\text { transferase activity, } \\
\text { transferring acyl } \\
\text { groups }\end{array}$ \\
\hline IPR018089 & $\begin{array}{l}\text { Orotidine 5'-phosphate } \\
\text { decarboxylase, active site }\end{array}$ & PS00156 & $\begin{array}{l}\text { 'de novo' pyrimidine } \\
\text { nucleobase } \\
\text { biosynthetic process } \\
\text { orotidine-5'-phosphate } \\
\text { decarboxylase activity }\end{array}$ \\
\hline IPR018114 & $\begin{array}{l}\text { Serine proteases, trypsin family, } \\
\text { histidine active site }\end{array}$ & PS00134 & $\begin{array}{l}\text { proteolysis } \\
\text { serine-type } \\
\text { endopeptidase activity }\end{array}$ \\
\hline IPR018117 & $\begin{array}{l}\text { DNA methylase, C- } 5 \text { cytosine- } \\
\text { specific, active site }\end{array}$ & PS00094 & \\
\hline IPR018120 & $\begin{array}{l}\text { Glycoside hydrolase family } 1, \\
\text { active site }\end{array}$ & PS00572 & \\
\hline IPR018129 & $\begin{array}{l}\text { Phosphoenolpyruvate carboxylase, } \\
\text { Lys active site }\end{array}$ & PS00781 & \\
\hline IPR018148 & Methylglyoxal synthase, active site & PS01335 & $\begin{array}{l}\text { methylglyoxal } \\
\text { biosynthetic process } \\
\text { methylglyoxal } \\
\text { synthase activity }\end{array}$ \\
\hline IPR018177 & $\begin{array}{l}\text { L-lactate dehydrogenase, active } \\
\text { site }\end{array}$ & PS00064 & $\begin{array}{l}\text { oxidation-reduction } \\
\text { process } \\
\text { L-lactate } \\
\text { dehydrogenase } \\
\text { activity }\end{array}$ \\
\hline IPR018187 & Asp/Glu racemase, active site 1 & PS00923 & \\
\hline IPR018188 & Ribonuclease $\mathrm{T} 2$, His active site 1 & PS00530 & $\begin{array}{l}\text { RNA binding } \\
\text { ribonuclease T2 } \\
\text { activity }\end{array}$ \\
\hline IPR018201 & Beta-ketoacyl synthase, active site & PS00606 & \\
\hline IPR018202 & $\begin{array}{l}\text { Serine carboxypeptidase, serine } \\
\text { active site }\end{array}$ & PS00131 & \\
\hline IPR018204 & $\begin{array}{l}\text { Tryptophan synthase, alpha chain, } \\
\text { active site }\end{array}$ & PS00167 & $\begin{array}{l}\text { tryptophan synthase } \\
\text { activity }\end{array}$ \\
\hline IPR018208 & $\begin{array}{l}\text { Glycoside hydrolase family } 11 \text {, } \\
\text { active site } 1\end{array}$ & PS00776 & \\
\hline IPR018209 & Pyruvate kinase, active site & PS00110 & $\begin{array}{l}\text { glycolytic process } \\
\text { pyruvate kinase } \\
\text { activity }\end{array}$ \\
\hline IPR018215 & ClpP, Ser active site & PS00381 & \\
\hline
\end{tabular}


Supplementary Data Set 1:

\begin{tabular}{|c|c|c|c|}
\hline IPR018221 & $\begin{array}{l}\text { Glycoside hydrolase family } 9 \text {, His } \\
\text { active site }\end{array}$ & PS00592 & \\
\hline IPR018225 & Transaldolase, active site & $\begin{array}{l}\text { PS00958 } \\
\text { PS01054 }\end{array}$ & $\begin{array}{l}\text { carbohydrate } \\
\text { metabolic process }\end{array}$ \\
\hline IPR018239 & $\begin{array}{l}\text { NAD-dependent DNA ligase, } \\
\text { active site }\end{array}$ & PS01055 & \\
\hline IPR018274 & PEP-utilising enzyme, active site & PS00370 & $\begin{array}{l}\text { phosphorylation } \\
\text { transferase activity, } \\
\text { transferring } \\
\text { phosphorus-containing } \\
\text { groups }\end{array}$ \\
\hline IPR018299 & Alkaline phosphatase, active site & PS00123 & phosphatase activity \\
\hline IPR018372 & $\begin{array}{l}\text { Chloramphenicol } \\
\text { acetyltransferase, active site }\end{array}$ & PS00100 & $\begin{array}{l}\text { chloramphenicol O- } \\
\text { acetyltransferase } \\
\text { activity }\end{array}$ \\
\hline IPR018508 & $\begin{array}{l}\text { 3-dehydroquinate dehydratase, } \\
\text { active site }\end{array}$ & PS01028 & $\begin{array}{l}\text { 3-dehydroquinate } \\
\text { dehydratase activity }\end{array}$ \\
\hline IPR018510 & $\begin{array}{l}\text { Diaminopimelate epimerase, active } \\
\text { site }\end{array}$ & PS01326 & $\begin{array}{l}\text { lysine biosynthetic } \\
\text { process via } \\
\text { diaminopimelate } \\
\text { diaminopimelate } \\
\text { epimerase activity } \\
\text { cytoplasm }\end{array}$ \\
\hline IPR018521 & DNA topoisomerase I, active site & PS00176 & $\begin{array}{l}\text { DNA topological } \\
\text { change } \\
\text { DNA binding } \\
\text { DNA topoisomerase } \\
\text { type I (single strand } \\
\text { cut, ATP-independent) } \\
\text { activity }\end{array}$ \\
\hline IPR018524 & $\begin{array}{l}\text { DNA/RNA non-specific } \\
\text { endonuclease, active site }\end{array}$ & PS01070 & $\begin{array}{l}\text { hydrolase activity } \\
\text { metal ion binding } \\
\text { nucleic acid binding }\end{array}$ \\
\hline IPR019756 & $\begin{array}{l}\text { Peptidase S26A, signal peptidase I, } \\
\text { serine active site }\end{array}$ & PS00501 & $\begin{array}{l}\text { serine-type peptidase } \\
\text { activity } \\
\text { integral component of } \\
\text { membrane }\end{array}$ \\
\hline IPR019757 & $\begin{array}{l}\text { Peptidase S26A, signal peptidase I, } \\
\text { lysine active site }\end{array}$ & PS00760 & $\begin{array}{l}\text { serine-type peptidase } \\
\text { activity } \\
\text { integral component of } \\
\text { membrane }\end{array}$ \\
\hline IPR019772 & Ferrochelatase, active site & PS00534 & $\begin{array}{l}\text { heme biosynthetic } \\
\text { process } \\
\text { ferrochelatase activity }\end{array}$ \\
\hline IPR019779 & $\begin{array}{l}\text { Galactose-1-phosphate uridyl } \\
\text { transferase, class I His-active site }\end{array}$ & PS00117 & \\
\hline
\end{tabular}


Supplementary Data Set 1:

\begin{tabular}{|c|c|c|c|}
\hline IPR019794 & Peroxidase, active site & PS00436 & $\begin{array}{l}\text { oxidation-reduction } \\
\text { process } \\
\text { peroxidase activity }\end{array}$ \\
\hline IPR019796 & $\begin{array}{l}\text { Glucose-6-phosphate } \\
\text { dehydrogenase, active site }\end{array}$ & PS00069 & $\begin{array}{l}\text { glucose metabolic } \\
\text { process } \\
\text { oxidation-reduction } \\
\text { process } \\
\text { glucose-6-phosphate } \\
\text { dehydrogenase } \\
\text { activity }\end{array}$ \\
\hline IPR019800 & $\begin{array}{l}\text { Glycoside hydrolase, family } 3 \text {, } \\
\text { active site }\end{array}$ & PS00775 & $\begin{array}{l}\text { carbohydrate } \\
\text { metabolic process } \\
\text { hydrolase activity, } \\
\text { hydrolyzing O- } \\
\text { glycosyl compounds }\end{array}$ \\
\hline IPR019810 & Citrate synthase active site & PS00480 & $\begin{array}{l}\text { tricarboxylic acid } \\
\text { cycle } \\
\text { transferase activity, } \\
\text { transferring acyl } \\
\text { groups, acyl groups } \\
\text { converted into alkyl } \\
\text { on transfer }\end{array}$ \\
\hline IPR019826 & $\begin{array}{l}\text { Carboxylesterase type } \mathrm{B} \text {, active } \\
\text { site }\end{array}$ & PS00122 & \\
\hline IPR020003 & $\begin{array}{l}\text { ATPase, alpha/beta subunit, } \\
\text { nucleotide-binding domain, active } \\
\text { site }\end{array}$ & PS00152 & ATP binding \\
\hline IPR020548 & $\begin{array}{l}\text { Fructose-1,6-bisphosphatase, } \\
\text { active site }\end{array}$ & PS00124 & $\begin{array}{l}\text { carbohydrate } \\
\text { metabolic process } \\
\text { phosphoric ester } \\
\text { hydrolase activity }\end{array}$ \\
\hline IPR020610 & Thiolase, active site & PS00099 & $\begin{array}{l}\text { transferase activity, } \\
\text { transferring acyl } \\
\text { groups other than } \\
\text { amino-acyl groups }\end{array}$ \\
\hline IPR020615 & $\begin{array}{l}\text { Thiolase, acyl-enzyme } \\
\text { intermediate active site }\end{array}$ & PS00098 & $\begin{array}{l}\text { transferase activity, } \\
\text { transferring acyl } \\
\text { groups other than } \\
\text { amino-acyl groups }\end{array}$ \\
\hline IPR020625 & $\begin{array}{l}\text { Schiff base-forming aldolase, } \\
\text { active site }\end{array}$ & PS00666 & lyase activity \\
\hline IPR020827 & $\begin{array}{l}\text { Asparaginase/glutaminase, active } \\
\text { site } 1\end{array}$ & PS00144 & $\begin{array}{l}\text { cellular amino acid } \\
\text { metabolic process }\end{array}$ \\
\hline IPR020830 & $\begin{array}{l}\text { Glyceraldehyde } 3 \text {-phosphate } \\
\text { dehydrogenase, active site }\end{array}$ & PS00071 & $\begin{array}{l}\text { oxidation-reduction } \\
\text { process } \\
\text { oxidoreductase }\end{array}$ \\
\hline
\end{tabular}




\begin{tabular}{|c|c|c|c|}
\hline & & & $\begin{array}{l}\text { activity, acting on the } \\
\text { aldehyde or oxo group } \\
\text { of donors, NAD or } \\
\text { NADP as acceptor }\end{array}$ \\
\hline IPR020861 & $\begin{array}{l}\text { Triosephosphate isomerase, active } \\
\text { site }\end{array}$ & PS00171 & $\begin{array}{l}\text { triose-phosphate } \\
\text { isomerase activity }\end{array}$ \\
\hline IPR020878 & $\begin{array}{l}\text { Ribulose bisphosphate } \\
\text { carboxylase, large chain, active } \\
\text { site }\end{array}$ & PS00157 & $\begin{array}{l}\text { carbon fixation } \\
\text { magnesium ion } \\
\text { binding } \\
\text { ribulose-bisphosphate } \\
\text { carboxylase activity }\end{array}$ \\
\hline IPR020940 & Thymidylate synthase, active site & PS00091 & $\begin{array}{l}\text { dTMP biosynthetic } \\
\text { process } \\
\text { thymidylate synthase } \\
\text { activity }\end{array}$ \\
\hline IPR022313 & $\begin{array}{l}\text { Phenylalanine/histidine ammonia- } \\
\text { lyases, active site }\end{array}$ & PS00488 & $\begin{array}{l}\text { ammonia-lyase } \\
\text { activity }\end{array}$ \\
\hline IPR022398 & $\begin{array}{l}\text { Peptidase S8, subtilisin, His-active } \\
\text { site }\end{array}$ & PS00137 & \\
\hline IPR022415 & $\begin{array}{l}\text { ATP:guanido phosphotransferase } \\
\text { active site }\end{array}$ & PS00112 & $\begin{array}{l}\text { kinase activity } \\
\text { transferase activity, } \\
\text { transferring } \\
\text { phosphorus-containing } \\
\text { groups }\end{array}$ \\
\hline IPR022469 & $\begin{array}{l}\text { 6-pyruvoyl tetrahydropterin } \\
\text { synthase, histidine active site }\end{array}$ & PS00988 & $\begin{array}{l}\text { tetrahydrobiopterin } \\
\text { biosynthetic process } \\
6- \\
\text { pyruvoyltetrahydropte } \\
\text { rin synthase activity }\end{array}$ \\
\hline IPR022470 & $\begin{array}{l}\text { 6-pyruvoyl tetrahydropterin } \\
\text { synthase, cysteine active site }\end{array}$ & PS00987 & $\begin{array}{l}\text { tetrahydrobiopterin } \\
\text { biosynthetic process } \\
6- \\
\text { pyruvoyltetrahydropte } \\
\text { rin synthase activity }\end{array}$ \\
\hline IPR023005 & $\begin{array}{l}\text { Nucleoside diphosphate kinase, } \\
\text { active site }\end{array}$ & PS00469 & \\
\hline IPR023011 & $\begin{array}{l}\text { ATP synthase, F0 complex, } \\
\text { subunit A, active site }\end{array}$ & PS00449 & \\
\hline IPR023013 & $\begin{array}{l}\mathrm{N} \text {-acetyl-gamma-glutamyl- } \\
\text { phosphate reductase, active site }\end{array}$ & PS01224 & \begin{tabular}{|l|} 
oxidation-reduction \\
process \\
N-acetyl-gamma- \\
glutamyl-phosphate \\
reductase activity
\end{tabular} \\
\hline IPR023232 & $\begin{array}{l}\text { Glycoside hydrolase, family } 2 \text {, } \\
\text { active site }\end{array}$ & PS00608 & \\
\hline IPR023313 & Ubiquitin-conjugating enzyme, & PS00183 & \\
\hline
\end{tabular}


Supplementary Data Set 1:

\begin{tabular}{|c|c|c|c|}
\hline & active site & & \\
\hline IPR023406 & $\begin{array}{l}\text { DNA topoisomerase, type IA, } \\
\text { active site }\end{array}$ & PS00396 & $\begin{array}{l}\text { DNA topoisomerase } \\
\text { type I (single strand } \\
\text { cut, ATP-independent) } \\
\text { activity }\end{array}$ \\
\hline IPR023411 & Ribonuclease A, active site & PS00127 & \\
\hline IPR023650 & Beta-lactamase, class-A active site & PS00146 & \\
\hline IPR023827 & $\begin{array}{l}\text { Peptidase S8, subtilisin, Asp-active } \\
\text { site }\end{array}$ & PS00136 & \\
\hline IPR023828 & $\begin{array}{l}\text { Peptidase S8, subtilisin, Ser-active } \\
\text { site }\end{array}$ & PS00138 & \\
\hline IPR024708 & Catalase active site & PS00438 & catalase activity \\
\hline IPR025660 & $\begin{array}{l}\text { Cysteine peptidase, histidine active } \\
\text { site }\end{array}$ & PS00639 & \\
\hline IPR025661 & $\begin{array}{l}\text { Cysteine peptidase, asparagine } \\
\text { active site }\end{array}$ & PS00640 & \\
\hline IPR027475 & $\begin{array}{l}\text { Asparaginase/glutaminase, active } \\
\text { site } 2\end{array}$ & PS00917 & \\
\hline IPR028301 & $\begin{array}{l}\text { Serine proteases, V8 family, } \\
\text { histidine active site }\end{array}$ & PS00672 & \\
\hline IPR029759 & Glutathione peroxidase active site & PS00460 & \\
\hline IPR030390 & $\begin{array}{l}\text { RNA methyltransferase TrmA, } \\
\text { active site }\end{array}$ & PS01230 & \\
\hline IPR030458 & $\begin{array}{l}\text { Glycosyl hydrolases family } 31 \text {, } \\
\text { active site }\end{array}$ & PS00129 & \\
\hline IPR030475 & $\begin{array}{l}\text { Ribonucleotide reductase small } \\
\text { subunit, acitve site }\end{array}$ & PS00368 & \\
\hline IPR030656 & $\begin{array}{l}\text { Delta-aminolevulinic acid } \\
\text { dehydratase, active site }\end{array}$ & PS00169 & \\
\hline IPR031158 & $\begin{array}{l}\text { Glycosyl hydrolases family } 10, \\
\text { active site }\end{array}$ & PS00591 & \\
\hline IPR031337 & KDPG/KHG aldolase, active site 1 & PS00159 & \\
\hline IPR031338 & KDPG/KHG aldolase, active site 2 & PS00160 & \\
\hline IPR033112 & $\begin{array}{l}\text { Phospholipase A2, aspartic acid } \\
\text { active site }\end{array}$ & PS00119 & \\
\hline IPR033113 & $\begin{array}{l}\text { Phospholipase } \mathrm{A} 2 \text {, histidine active } \\
\text { site }\end{array}$ & PS00118 & \\
\hline IPR033116 & $\begin{array}{l}\text { Serine proteases, trypsin family, } \\
\text { serine active site }\end{array}$ & PS00135 & \\
\hline IPR033119 & $\begin{array}{l}\text { Glycoside hydrolase family } 11, \\
\text { active site } 2\end{array}$ & PS00777 & \\
\hline IPR033124 & $\begin{array}{l}\text { Serine carboxypeptidases, histidine } \\
\text { active site }\end{array}$ & PS00560 & \\
\hline IPR033126 & $\begin{array}{l}\text { Glycosyl hydrolases family 9, } \\
\text { Asp/Glu active sites }\end{array}$ & PS00698 & \\
\hline
\end{tabular}


Supplementary Data Set 1:

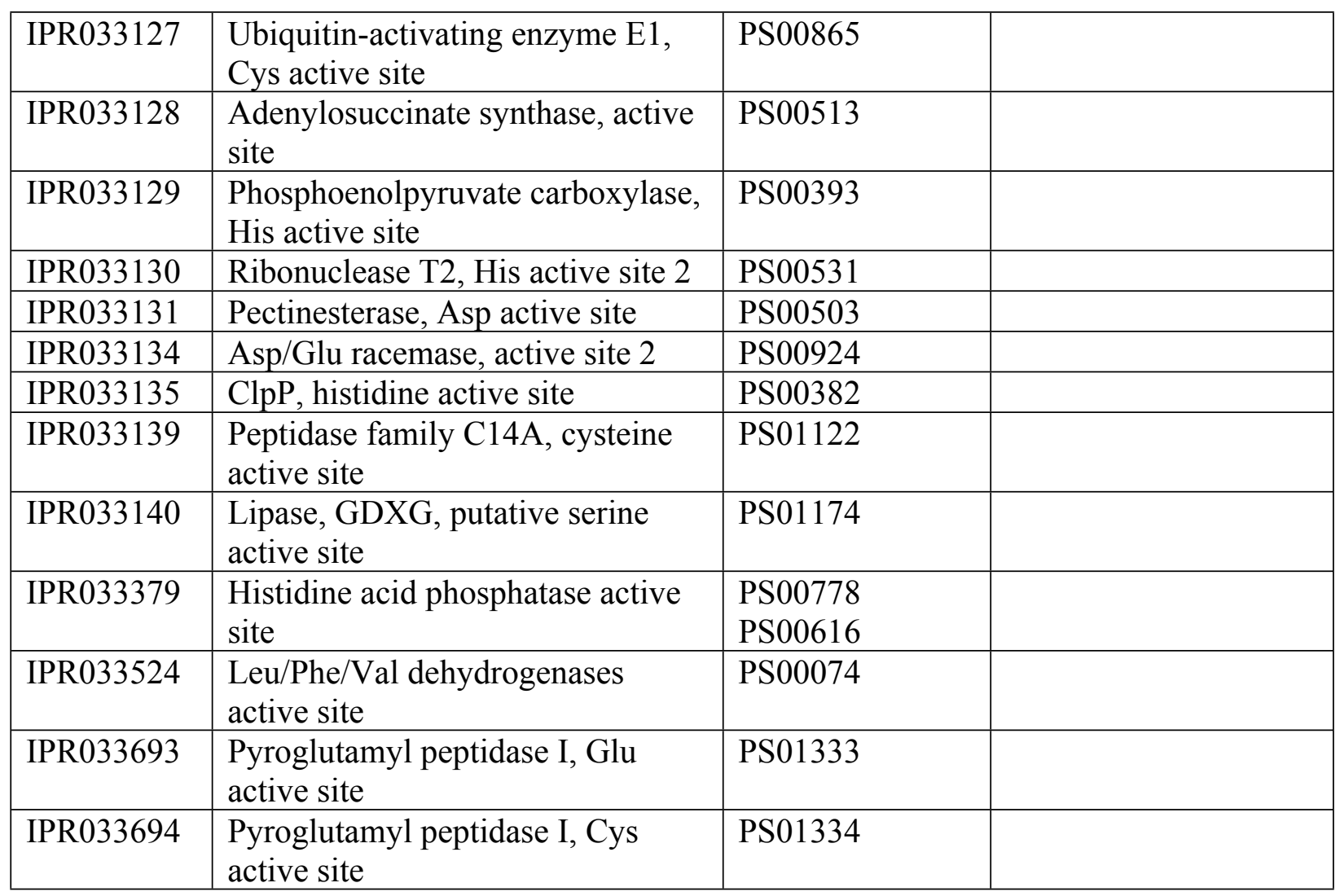


Supplementary Data Set 1:

Table S3: List of binding sites in the protein H3GZF6.

\begin{tabular}{|c|c|c|c|}
\hline ACCESSION & NAME & $\begin{array}{l}\text { INTEGRATED } \\
\text { SIGNATURE(S) }\end{array}$ & FEATURES \\
\hline IPR000048 & $\begin{array}{l}\text { IQ motif, EF-hand binding } \\
\text { site }\end{array}$ & $\begin{array}{l}\text { SM00015 } \\
\text { PF00612 } \\
\text { PS50096 }\end{array}$ & protein binding \\
\hline IPR000222 & $\begin{array}{l}\text { PPM-type phosphatase, } \\
\text { divalent cation binding }\end{array}$ & PS01032 & cation binding \\
\hline IPR000634 & $\begin{array}{l}\text { Serine/threonine dehydratase, } \\
\text { pyridoxal-phosphate-binding } \\
\text { site }\end{array}$ & PS00165 & $\begin{array}{l}\text { cellular amino acid } \\
\text { metabolic process } \\
\text { pyridoxal phosphate binding }\end{array}$ \\
\hline IPR001216 & $\begin{array}{l}\text { Cysteine } \\
\text { synthase/cystathionine beta- } \\
\text { synthase, pyridoxal- } \\
\text { phosphate attachment site }\end{array}$ & PS00901 & $\begin{array}{l}\text { cysteine biosynthetic } \\
\text { process from serine }\end{array}$ \\
\hline IPR001431 & $\begin{array}{l}\text { Peptidase M16, zinc-binding } \\
\text { site }\end{array}$ & PS00143 & $\begin{array}{l}\text { proteolysis } \\
\text { metalloendopeptidase } \\
\text { activity }\end{array}$ \\
\hline IPR001505 & Copper centre $\mathrm{Cu}(\mathrm{A})$ & PS00078 & copper ion binding \\
\hline IPR001882 & Biotin-binding site & PS00188 & \\
\hline IPR001917 & $\begin{array}{l}\text { Aminotransferase, class-II, } \\
\text { pyridoxal-phosphate binding } \\
\text { site }\end{array}$ & PS00599 & transferase activity \\
\hline IPR002226 & Catalase haem-binding site & PS00437 & heme binding \\
\hline IPR002355 & $\begin{array}{l}\text { Multicopper oxidase, copper- } \\
\text { binding site }\end{array}$ & PS00080 & copper ion binding \\
\hline IPR003016 & $\begin{array}{l}\text { 2-oxo acid dehydrogenase, } \\
\text { lipoyl-binding site }\end{array}$ & PS00189 & \\
\hline IPR003952 & $\begin{array}{l}\text { Fumarate reductase/succinate } \\
\text { dehydrogenase, FAD-binding } \\
\text { site }\end{array}$ & PS00504 & $\begin{array}{l}\text { oxidation-reduction process } \\
\text { oxidoreductase activity }\end{array}$ \\
\hline IPR004035 & $\begin{array}{l}\text { Endonuclease III, iron- } \\
\text { sulphur binding site }\end{array}$ & PS00764 & \\
\hline IPR004163 & $\begin{array}{l}\text { Coenzyme A transferase } \\
\text { binding site }\end{array}$ & PS01273 & CoA-transferase activity \\
\hline IPR004838 & $\begin{array}{l}\text { Aminotransferases, class-I, } \\
\text { pyridoxal-phosphate-binding } \\
\text { site }\end{array}$ & PS00105 & $\begin{array}{l}\text { biosynthetic process } \\
\text { catalytic activity } \\
\text { pyridoxal phosphate binding }\end{array}$ \\
\hline IPR006058 & $\begin{array}{l}\text { 2Fe-2S ferredoxin, iron- } \\
\text { sulphur binding site }\end{array}$ & PS00197 & $\begin{array}{l}2 \text { iron, } 2 \text { sulfur cluster } \\
\text { binding }\end{array}$ \\
\hline IPR006066 & $\begin{array}{l}\text { Nitrite/sulphite reductase } \\
\text { iron-sulphur/sirohaem- } \\
\text { binding site }\end{array}$ & $\begin{array}{l}\text { PR00397 } \\
\text { PS00365 }\end{array}$ & $\begin{array}{l}\text { oxidation-reduction process } \\
\text { heme binding } \\
\text { iron-sulfur cluster binding } \\
\text { oxidoreductase activity }\end{array}$ \\
\hline
\end{tabular}


Supplementary Data Set 1:

\begin{tabular}{|c|c|c|c|}
\hline IPR006093 & $\begin{array}{l}\text { Oxygen oxidoreductase } \\
\text { covalent FAD-binding site }\end{array}$ & PS00862 & $\begin{array}{l}\text { oxidation-reduction process } \\
\text { oxidoreductase activity }\end{array}$ \\
\hline IPR006184 & $\begin{array}{l}\text { 6-phosphogluconate-binding } \\
\text { site }\end{array}$ & PS00461 & $\begin{array}{l}\text { oxidation-reduction process } \\
\text { pentose-phosphate shunt } \\
\text { phosphogluconate } \\
\text { dehydrogenase } \\
\text { (decarboxylating) activity }\end{array}$ \\
\hline IPR013516 & $\begin{array}{l}\text { Phytochrome chromophore } \\
\text { binding site }\end{array}$ & PS00245 & $\begin{array}{l}\text { protein-chromophore } \\
\text { linkage }\end{array}$ \\
\hline IPR013838 & $\begin{array}{l}\text { Beta tubulin, autoregulation } \\
\text { binding site }\end{array}$ & PS00228 & \\
\hline IPR015881 & $\begin{array}{l}\text { Aromatic-ring-hydroxylating } \\
\text { dioxygenase, } 2 \text { Fe-2S-binding } \\
\text { site }\end{array}$ & PS00570 & $\begin{array}{l}\text { oxidation-reduction process } \\
2 \text { iron, } 2 \text { sulfur cluster } \\
\text { binding } \\
\text { iron ion binding }\end{array}$ \\
\hline IPR015887 & $\begin{array}{l}\text { DNA glycosylase/AP lyase, } \\
\text { zinc finger domain, DNA- } \\
\text { binding site }\end{array}$ & PS01242 & $\begin{array}{l}\text { DNA repair } \\
\text { DNA binding } \\
\text { DNA-(apurinic or } \\
\text { apyrimidinic site) } \\
\text { endonuclease activity } \\
\text { hydrolase activity, } \\
\text { hydrolyzing N-glycosyl } \\
\text { compounds } \\
\text { zinc ion binding }\end{array}$ \\
\hline IPR016131 & $\begin{array}{l}\text { Haemerythrin, iron-binding } \\
\text { site }\end{array}$ & PS00550 & metal ion binding \\
\hline IPR016192 & $\begin{array}{l}\text { APOBEC/CMP deaminase, } \\
\text { zinc-binding }\end{array}$ & PS00903 & $\begin{array}{l}\text { hydrolase activity } \\
\text { zinc ion binding }\end{array}$ \\
\hline IPR017441 & $\begin{array}{l}\text { Protein kinase, ATP binding } \\
\text { site }\end{array}$ & PS00107 & ATP binding \\
\hline IPR017947 & $\begin{array}{l}\text { Aryldialkylphosphatase, zinc- } \\
\text { binding site }\end{array}$ & PS01322 & $\begin{array}{l}\text { catabolic process } \\
\text { hydrolase activity, acting on } \\
\text { ester bonds } \\
\text { zinc ion binding }\end{array}$ \\
\hline IPR018064 & $\begin{array}{l}\text { Metallothionein, vertebrate, } \\
\text { metal binding site }\end{array}$ & PS00203 & \\
\hline IPR018136 & $\begin{array}{l}\text { Aconitase family, } 4 \mathrm{Fe}-4 \mathrm{~S} \\
\text { cluster binding site }\end{array}$ & $\begin{array}{l}\text { PS00450 } \\
\text { PS01244 }\end{array}$ & \\
\hline IPR018152 & $\begin{array}{l}\text { Superoxide dismutase, } \\
\text { copper/zinc, binding site }\end{array}$ & $\begin{array}{l}\text { PS00087 } \\
\text { PS00332 }\end{array}$ & $\begin{array}{l}\text { oxidation-reduction process } \\
\text { superoxide dismutase } \\
\text { activity }\end{array}$ \\
\hline IPR018194 & $\begin{array}{l}\text { Nickel-dependent } \\
\text { hydrogenase, large subunit, } \\
\text { nickel binding site }\end{array}$ & $\begin{array}{l}\text { PS00507 } \\
\text { PS00508 }\end{array}$ & $\begin{array}{l}\text { oxidation-reduction process } \\
\text { ferredoxin hydrogenase } \\
\text { activity } \\
\text { nickel cation binding }\end{array}$ \\
\hline IPR018195 & Transferrin family, iron & PS00205 & extracellular region \\
\hline
\end{tabular}


Supplementary Data Set 1:

\begin{tabular}{|c|c|c|c|}
\hline & binding site & $\begin{array}{l}\text { PS00206 } \\
\text { PS00207 }\end{array}$ & \\
\hline IPR018220 & $\begin{array}{l}\text { Adenylosuccinate synthase, } \\
\text { GTP-binding site }\end{array}$ & PS01266 & GTP binding \\
\hline IPR018229 & $\begin{array}{l}\text { Rhodopsin, retinal binding } \\
\text { site }\end{array}$ & $\begin{array}{l}\text { PS00327 } \\
\text { PS00950 }\end{array}$ & $\begin{array}{l}\text { ion transport } \\
\text { ion channel activity } \\
\text { membrane }\end{array}$ \\
\hline IPR018246 & $\begin{array}{l}\text { AP endonuclease } 2 \text {, zinc } \\
\text { binding site }\end{array}$ & $\begin{array}{l}\text { PS00729 } \\
\text { PS00730 } \\
\text { PS00731 }\end{array}$ & zinc ion binding \\
\hline IPR018247 & $\begin{array}{l}\text { EF-Hand 1, calcium-binding } \\
\text { site }\end{array}$ & PS00018 & \\
\hline IPR018298 & $\begin{array}{l}\text { Adrenodoxin, iron-sulphur } \\
\text { binding site }\end{array}$ & PS00814 & $\begin{array}{l}2 \text { iron, } 2 \text { sulfur cluster } \\
\text { binding } \\
\text { electron transfer activity }\end{array}$ \\
\hline IPR018301 & $\begin{array}{l}\text { Aromatic amino acid } \\
\text { hydroxylase, iron/copper } \\
\text { binding site }\end{array}$ & PS00367 & $\begin{array}{l}\text { aromatic amino acid family } \\
\text { metabolic process } \\
\text { oxidation-reduction process } \\
\text { iron ion binding } \\
\text { monooxygenase activity }\end{array}$ \\
\hline IPR018349 & $\begin{array}{l}\text { Peptidase M24A, methionine } \\
\text { aminopeptidase, subfamily } 2 \text {, } \\
\text { binding site }\end{array}$ & PS01202 & \\
\hline IPR018506 & $\begin{array}{l}\text { Cytochrome b5, heme- } \\
\text { binding site }\end{array}$ & PS00191 & heme binding \\
\hline IPR018527 & Rubredoxin, iron-binding site & PS00202 & metal ion binding \\
\hline IPR019780 & $\begin{array}{l}\text { Germin, manganese binding } \\
\text { site }\end{array}$ & PS00725 & manganese ion binding \\
\hline IPR019789 & $\begin{array}{l}\text { Xylulose 5- } \\
\text { phosphate/Fructose 6- } \\
\text { phosphate phosphoketolase, } \\
\text { thiamine diphosphate binding } \\
\text { site }\end{array}$ & PS60003 & $\begin{array}{l}\text { carbohydrate metabolic } \\
\text { process } \\
\text { aldehyde-lyase activity }\end{array}$ \\
\hline IPR019793 & $\begin{array}{l}\text { Peroxidases heam-ligand } \\
\text { binding site }\end{array}$ & PS00435 & \\
\hline IPR019798 & $\begin{array}{l}\text { Serine } \\
\text { hydroxymethyltransferase, } \\
\text { pyridoxal phosphate binding } \\
\text { site }\end{array}$ & PS00096 & pyridoxal phosphate binding \\
\hline IPR019807 & Hexokinase, binding site & PS00378 & $\begin{array}{l}\text { glycolytic process } \\
\text { ATP binding } \\
\text { hexokinase activity }\end{array}$ \\
\hline IPR019824 & $\begin{array}{l}\text { Leghaemoglobin, iron- } \\
\text { binding site }\end{array}$ & PS00208 & $\begin{array}{l}\text { heme binding } \\
\text { oxygen binding }\end{array}$ \\
\hline IPR019825 & $\begin{array}{l}\text { Legume lectin, beta chain, } \\
\text { Mn/Ca-binding site }\end{array}$ & PS00307 & \\
\hline
\end{tabular}


Supplementary Data Set 1:

\begin{tabular}{|c|c|c|c|}
\hline IPR019833 & $\begin{array}{l}\text { Manganese/iron superoxide } \\
\text { dismutase, binding site }\end{array}$ & PS00088 & $\begin{array}{l}\text { oxidation-reduction process } \\
\text { superoxide metabolic } \\
\text { process } \\
\text { metal ion binding } \\
\text { superoxide dismutase } \\
\text { activity }\end{array}$ \\
\hline IPR019843 & $\begin{array}{l}\text { DNA polymerase family } \mathrm{X} \text {, } \\
\text { binding site }\end{array}$ & PS00522 & $\begin{array}{l}\text { nucleotidyltransferase } \\
\text { activity }\end{array}$ \\
\hline IPR020537 & $\begin{array}{l}\text { ATP synthase, F0 complex, } \\
\text { subunit C, DCCD-binding } \\
\text { site }\end{array}$ & PS00605 & \\
\hline IPR020563 & $\begin{array}{l}\text { Crossover junction } \\
\text { endodeoxyribonuclease } \\
\text { RuvC, magnesium-binding } \\
\text { site }\end{array}$ & PS01321 & $\begin{array}{l}\text { crossover junction } \\
\text { endodeoxyribonuclease } \\
\text { activity }\end{array}$ \\
\hline IPR020578 & $\begin{array}{l}\text { Aminotransferase class- } \mathrm{V}, \\
\text { pyridoxal-phosphate binding } \\
\text { site }\end{array}$ & PS00595 & \\
\hline IPR020583 & $\begin{array}{l}\text { Inositol monophosphatase, } \\
\text { metal-binding site }\end{array}$ & PS00629 & \\
\hline IPR020622 & $\begin{array}{l}\text { Alanine racemase, pyridoxal- } \\
\text { phosphate attachment site }\end{array}$ & PS00395 & \\
\hline IPR020789 & $\begin{array}{l}\text { RNA polymerases, subunit } \mathrm{N} \text {, } \\
\text { zinc binding site }\end{array}$ & PS01112 & $\begin{array}{l}\text { transcription, DNA- } \\
\text { templated } \\
\text { DNA binding } \\
\text { DNA-directed 5'-3' RNA } \\
\text { polymerase activity } \\
\text { zinc ion binding }\end{array}$ \\
\hline IPR020826 & Transketolase binding site & PS00802 & \\
\hline IPR020833 & $\begin{array}{l}\text { Lipoxygenase, iron binding } \\
\text { site }\end{array}$ & PS00711 & $\begin{array}{l}\text { oxidation-reduction process } \\
\text { metal ion binding } \\
\text { oxidoreductase activity, } \\
\text { acting on single donors with } \\
\text { incorporation of molecular } \\
\text { oxygen, incorporation of } \\
\text { two atoms of oxygen }\end{array}$ \\
\hline IPR020847 & $\begin{array}{l}\text { AP endonuclease } 1 \text {, binding } \\
\text { site }\end{array}$ & PS00726 & $\begin{array}{l}\text { DNA repair } \\
\text { DNA binding } \\
\text { endonuclease activity }\end{array}$ \\
\hline IPR020855 & $\begin{array}{l}\text { Ureohydrolase, manganese- } \\
\text { binding site }\end{array}$ & PS01053 & $\begin{array}{l}\text { hydrolase activity, acting on } \\
\text { carbon-nitrogen (but not } \\
\text { peptide) bonds, in linear } \\
\text { amidines } \\
\text { metal ion binding }\end{array}$ \\
\hline IPR020893 & $\begin{array}{l}\text { Cytochrome c oxidase, } \\
\text { subunit } \mathrm{Vb} \text {, zinc binding site }\end{array}$ & PS00848 & \\
\hline
\end{tabular}


Supplementary Data Set 1:

\begin{tabular}{|c|c|c|c|}
\hline IPR020969 & Ankyrin-G binding site & PF11956 & $\begin{array}{l}\text { potassium channel activity } \\
\text { membrane }\end{array}$ \\
\hline IPR021115 & $\begin{array}{l}\text { Pyridoxal-phosphate binding } \\
\text { site }\end{array}$ & PS00392 & carboxy-lyase activity \\
\hline IPR021158 & $\begin{array}{l}\text { Peptidase M10A, cysteine } \\
\text { switch, zinc binding site }\end{array}$ & PS00546 & $\begin{array}{l}\text { proteolysis } \\
\text { metalloendopeptidase } \\
\text { activity } \\
\text { zinc ion binding } \\
\text { extracellular matrix }\end{array}$ \\
\hline IPR022407 & $\begin{array}{l}\text { Oxidoreductase, } \\
\text { molybdopterin binding site }\end{array}$ & PS00559 & $\begin{array}{l}\text { oxidation-reduction process } \\
\text { molybdopterin cofactor } \\
\text { binding }\end{array}$ \\
\hline IPR022419 & $\begin{array}{l}\text { Porphobilinogen deaminase, } \\
\text { dipyrromethane cofactor } \\
\text { binding site }\end{array}$ & PS00533 & $\begin{array}{l}\text { peptidyl-pyrromethane } \\
\text { cofactor linkage } \\
\text { tetrapyrrole biosynthetic } \\
\text { process } \\
\text { hydroxymethylbilane } \\
\text { synthase activity }\end{array}$ \\
\hline IPR022653 & $\begin{array}{l}\text { Orn/DAP/Arg decarboxylase } \\
2 \text {, pyridoxal-phosphate } \\
\text { binding site }\end{array}$ & PS00878 & \\
\hline IPR023418 & $\begin{array}{l}\text { Transthyretin, thyroxine } \\
\text { binding site }\end{array}$ & PS00768 & \\
\hline IPR023615 & $\begin{array}{l}\text { Cytochrome c oxidase, } \\
\text { subunit I, copper-binding site }\end{array}$ & PS00077 & $\begin{array}{l}\text { oxidation-reduction process } \\
\text { cytochrome-c oxidase } \\
\text { activity }\end{array}$ \\
\hline IPR025662 & $\begin{array}{l}\text { Sigma-54 interaction domain, } \\
\text { ATP-binding site } 1\end{array}$ & PS00675 & \\
\hline IPR025943 & $\begin{array}{l}\text { Sigma-54 interaction domain, } \\
\text { ATP-binding site } 2\end{array}$ & PS00676 & \\
\hline IPR027430 & $\begin{array}{l}\text { Visual pigments (opsins) } \\
\text { retinal binding site }\end{array}$ & PS00238 & \\
\hline IPR027467 & $\begin{array}{l}\text { Molybdopterin } \\
\text { oxidoreductase, } \\
\text { molybdopterin cofactor } \\
\text { binding site }\end{array}$ & PS00551 & $\begin{array}{l}4 \text { iron, } 4 \text { sulfur cluster } \\
\text { binding }\end{array}$ \\
\hline IPR028871 & $\begin{array}{l}\text { Blue (type 1) copper protein, } \\
\text { binding site }\end{array}$ & PS00196 & \\
\hline IPR029754 & Urease nickel binding site & PS01120 & nickel cation binding \\
\hline IPR034408 & $\begin{array}{l}\text { Sulphate/thiosulphate-binding } \\
\text { site }\end{array}$ & PS00757 & sulfur compound binding \\
\hline
\end{tabular}


Supplementary Data Set 1:

Table S4: Post-translational modification (PTM) referring to the covalent and generally enzymatic modification of proteins following protein biosynthesis. Proteins are synthesized by ribosomes translating mRNA into polypeptide chains, which may then undergo PTM to form the mature protein product.

\begin{tabular}{|c|c|c|c|}
\hline ACCESSION & NAME & $\begin{array}{l}\text { INTEGRATED } \\
\text { SIGNATURE(S) }\end{array}$ & FEATURES \\
\hline IPR000152 & $\begin{array}{l}\text { EGF-type aspartate/asparagine hydroxylation } \\
\text { site }\end{array}$ & PS00010 & \\
\hline IPR001020 & $\begin{array}{l}\text { Phosphotransferase system, HPr histidine } \\
\text { phosphorylation site }\end{array}$ & PS00369 & \\
\hline IPR002114 & $\begin{array}{l}\text { Phosphotransferase system, HPr serine } \\
\text { phosphorylation site }\end{array}$ & PS00589 & \\
\hline IPR002332 & $\begin{array}{l}\text { Nitrogen regulatory protein } \mathrm{P}-\mathrm{II} \text {, urydylation } \\
\text { site }\end{array}$ & PS00496 & $\begin{array}{l}\text { regulation } \\
\text { of nitrogen } \\
\text { utilization } \\
\text { enzyme } \\
\text { regulator } \\
\text { activity }\end{array}$ \\
\hline IPR004091 & $\begin{array}{l}\text { Chemotaxis methyl-accepting receptor, } \\
\text { methyl-accepting site }\end{array}$ & PS00538 & \\
\hline IPR006141 & Intein $\mathrm{N}$-terminal splicing region & $\begin{array}{l}\text { TIGR01445 } \\
\text { PS50817 }\end{array}$ & $\begin{array}{l}\text { intein- } \\
\text { mediated } \\
\text { protein } \\
\text { splicing }\end{array}$ \\
\hline IPR006162 & Phosphopantetheine attachment site & PS00012 & \\
\hline IPR012902 & Prokaryotic N-terminal methylation site & $\begin{array}{l}\text { TIGR02532 } \\
\text { PF07963 } \\
\text { PS00409 }\end{array}$ & \\
\hline IPR018051 & $\begin{array}{l}\text { Surfactant-associated polypeptide, } \\
\text { palmitoylation site }\end{array}$ & PS00341 & $\begin{array}{l}\text { respiratory } \\
\text { gaseous } \\
\text { exchange by } \\
\text { respiratory } \\
\text { system } \\
\text { extracellular } \\
\text { region }\end{array}$ \\
\hline IPR018070 & Neuromedin $\mathrm{U}$, amidation site & PS00967 & \\
\hline IPR018243 & Neuromodulin, palmitoylation site & PS00412 & \\
\hline IPR018303 & P-type ATPase, phosphorylation site & PS00154 & \\
\hline IPR019736 & Synapsin, phosphorylation site & $\begin{array}{l}\text { PF10581 } \\
\text { PS00415 }\end{array}$ & \\
\hline IPR019769 & $\begin{array}{l}\text { Translation elongation factor, IF5A, hypusine } \\
\text { site }\end{array}$ & PS00302 & $\begin{array}{l}\text { positive } \\
\text { regulation } \\
\text { of }\end{array}$ \\
\hline
\end{tabular}


Supplementary Data Set 1:

\begin{tabular}{|l|l|l|l|}
\hline & & & $\begin{array}{l}\text { translational } \\
\text { elongation } \\
\text { positive } \\
\text { regulation } \\
\text { of } \\
\text { translational } \\
\text { termination } \\
\text { RNA } \\
\text { binding } \\
\text { ribosome } \\
\text { binding } \\
\text { translation } \\
\text { elongation } \\
\text { factor } \\
\text { activity }\end{array}$ \\
& & & \\
\hline IPR021020 & Adhesin, Dr family, signal peptide & PF12393 & \\
\hline IPR029259 & Rapamycin-insensitive companion of mTOR, & PF14665 & SM01309 \\
& phosphorylation-site & PS00413 & \\
\hline IPR033137 & Neuromodulin, phosphorylation site & & \\
\hline
\end{tabular}




\section{Supplementary Data Set 1:}

Table S5: Alignment of transglutaminase elicitor domain with 3tw5.

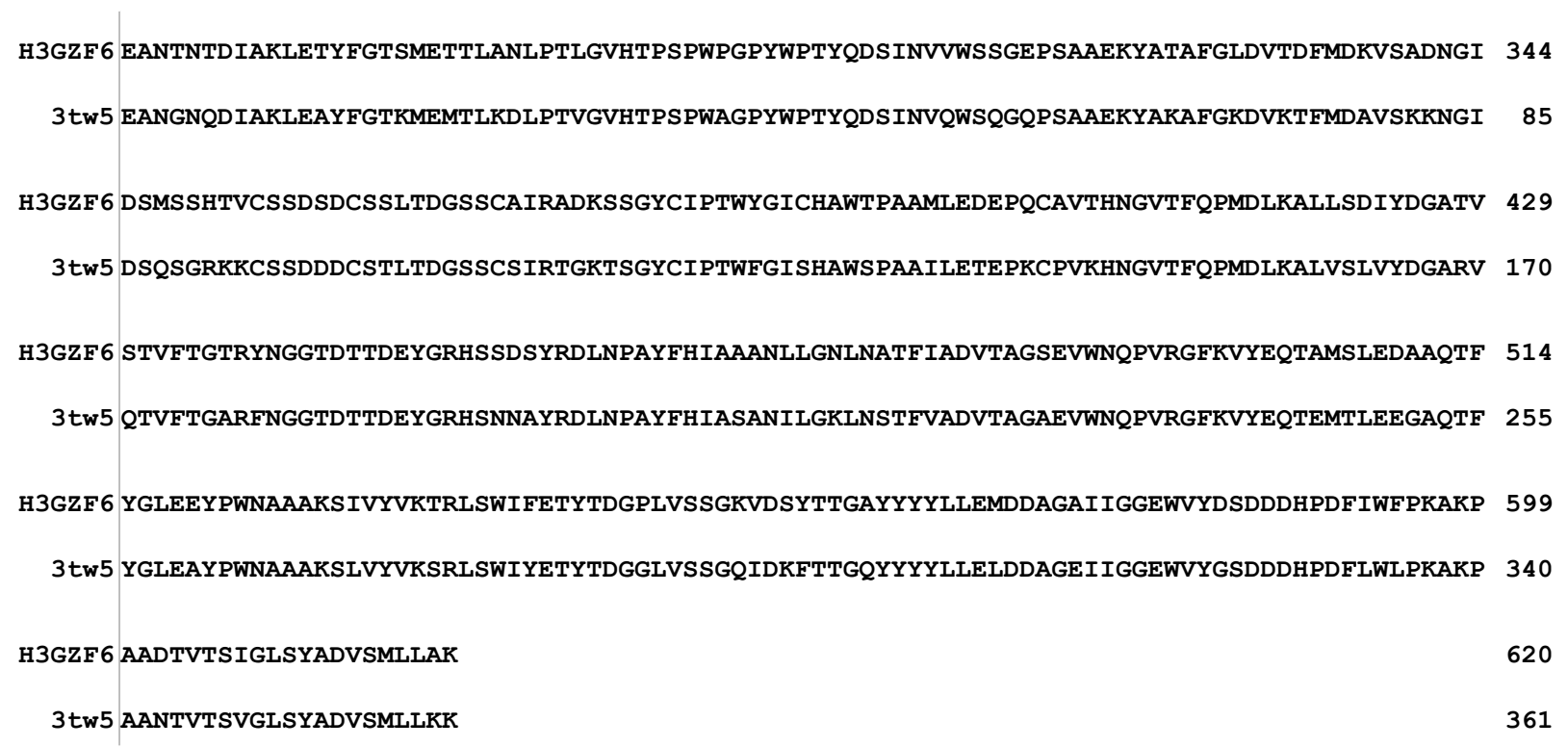


Supplementary Data Set 1:
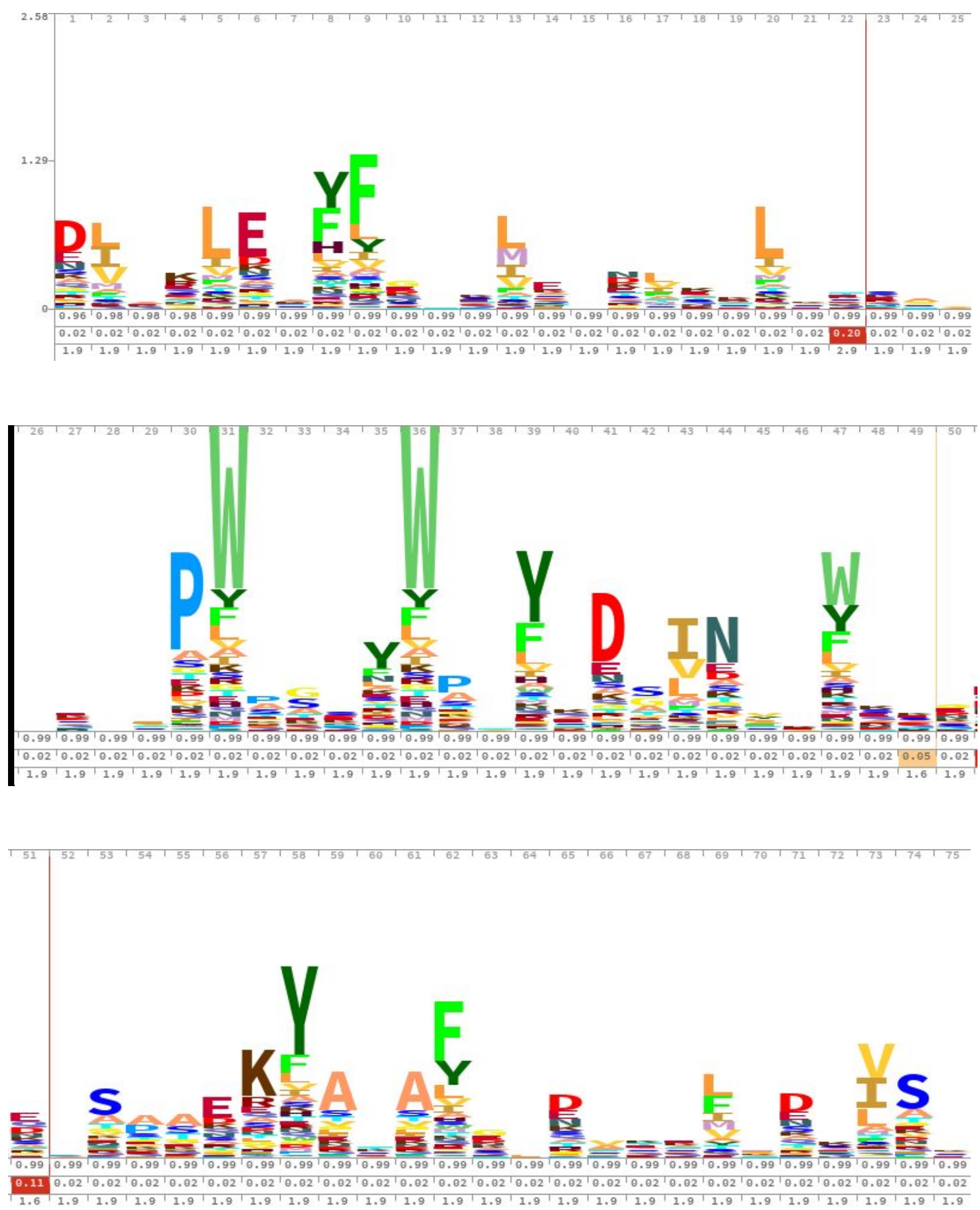
Supplementary Data Set 1:
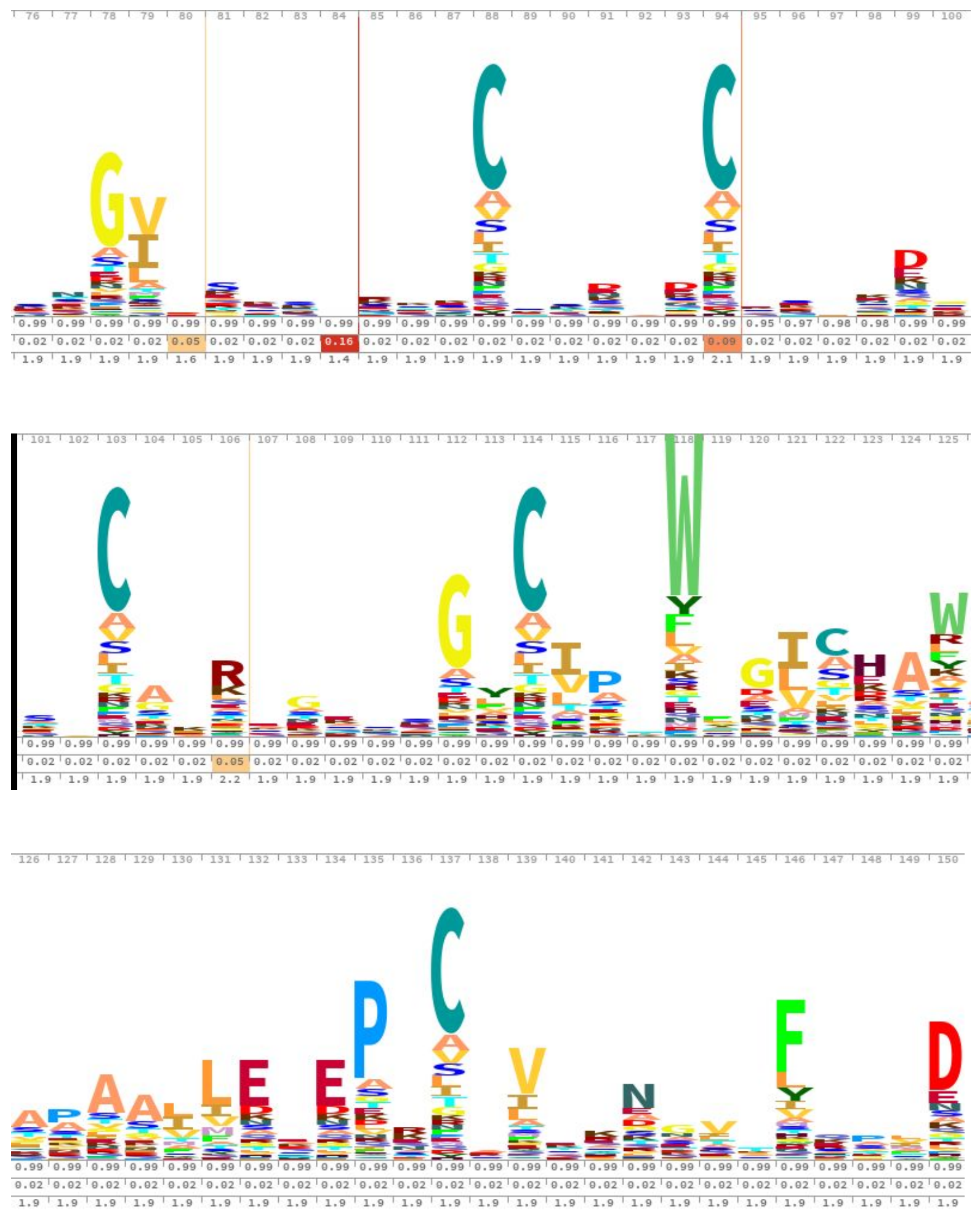

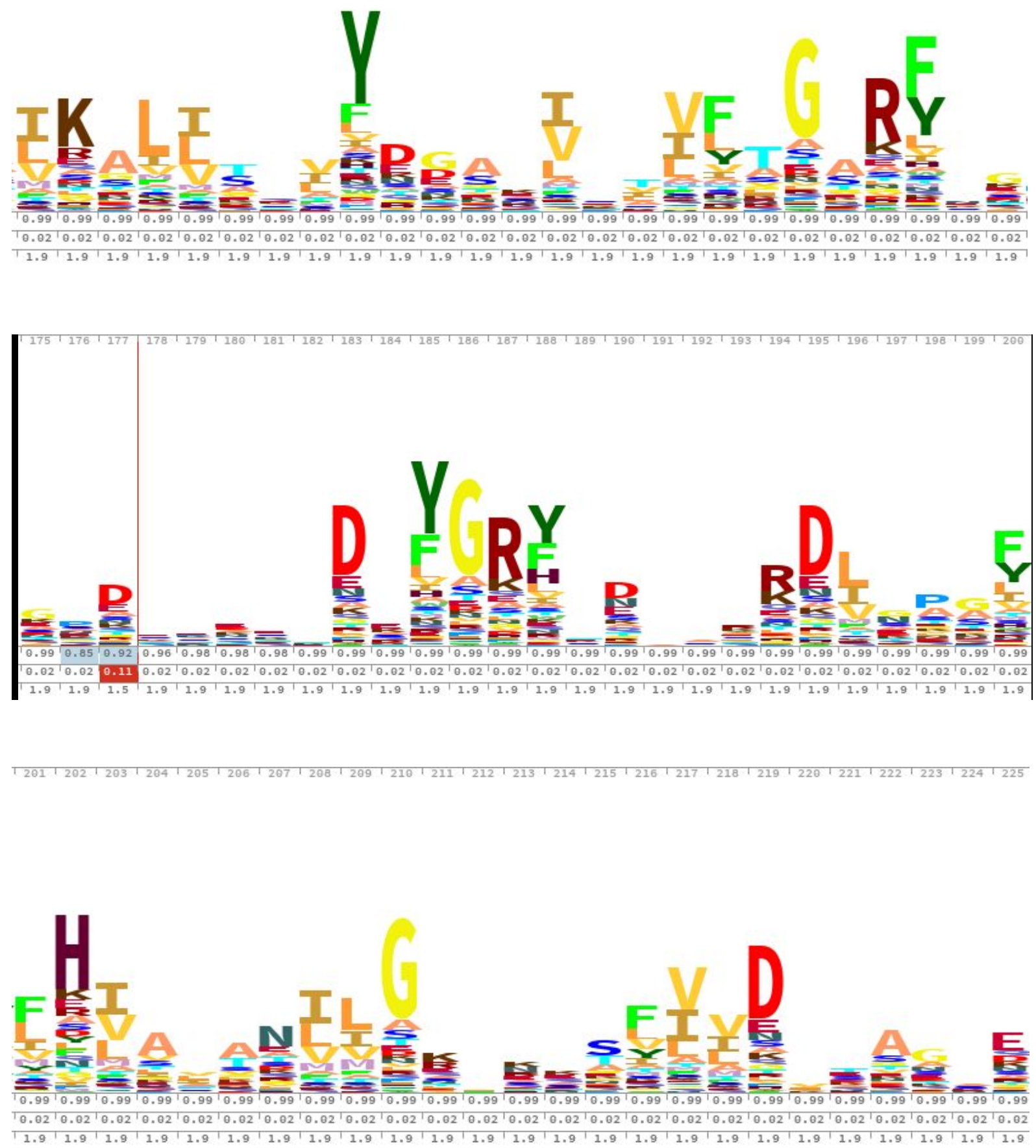
Supplementary Data Set 1:


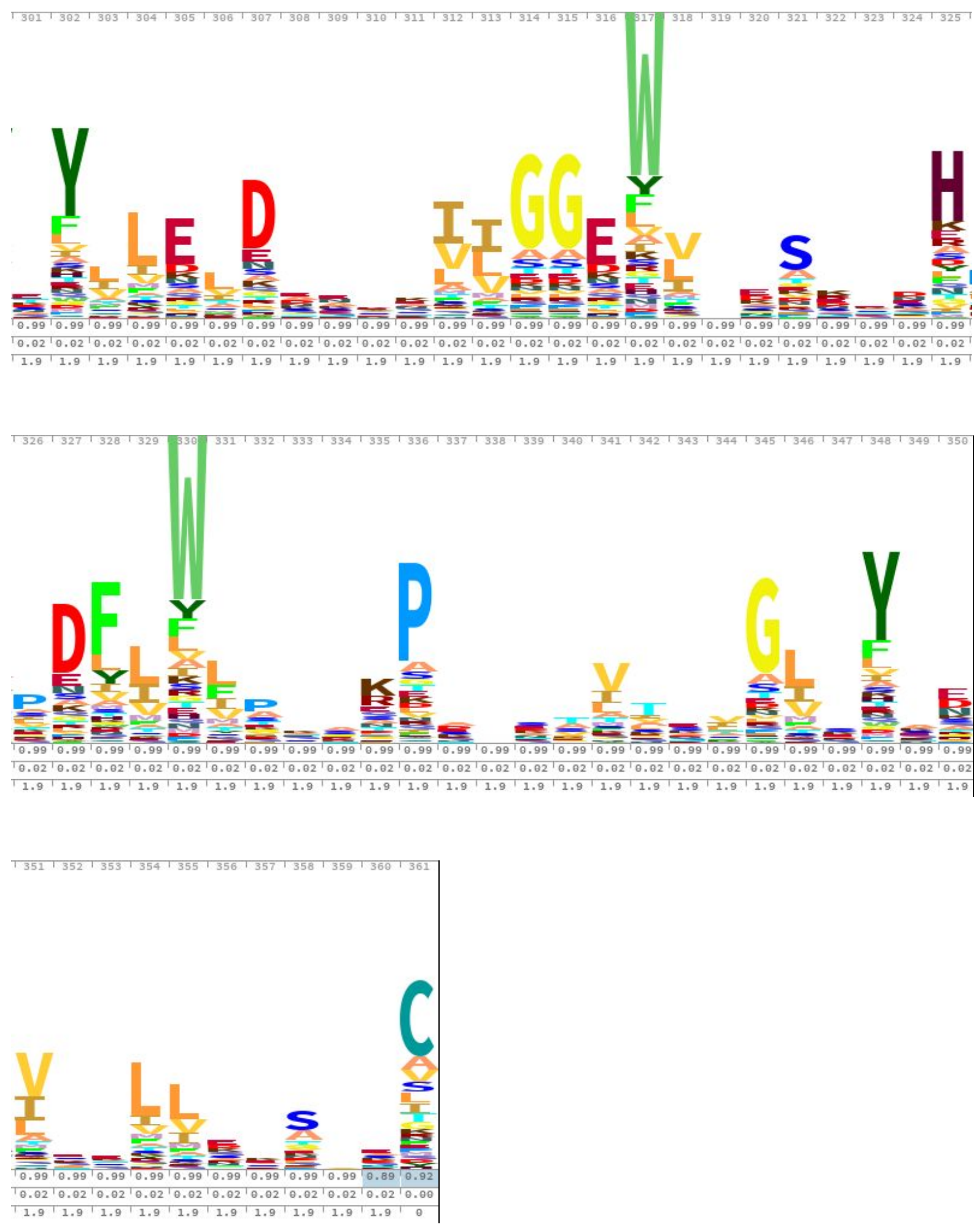

Figure S1: Hidden Markov Model (HMM) of H3GZF6 protein. The protein sequence is available on Uniprot at the URL 'https://www.uniprot.org/uniprot/H3GZF6'. 
Supplementary Data Set 1:

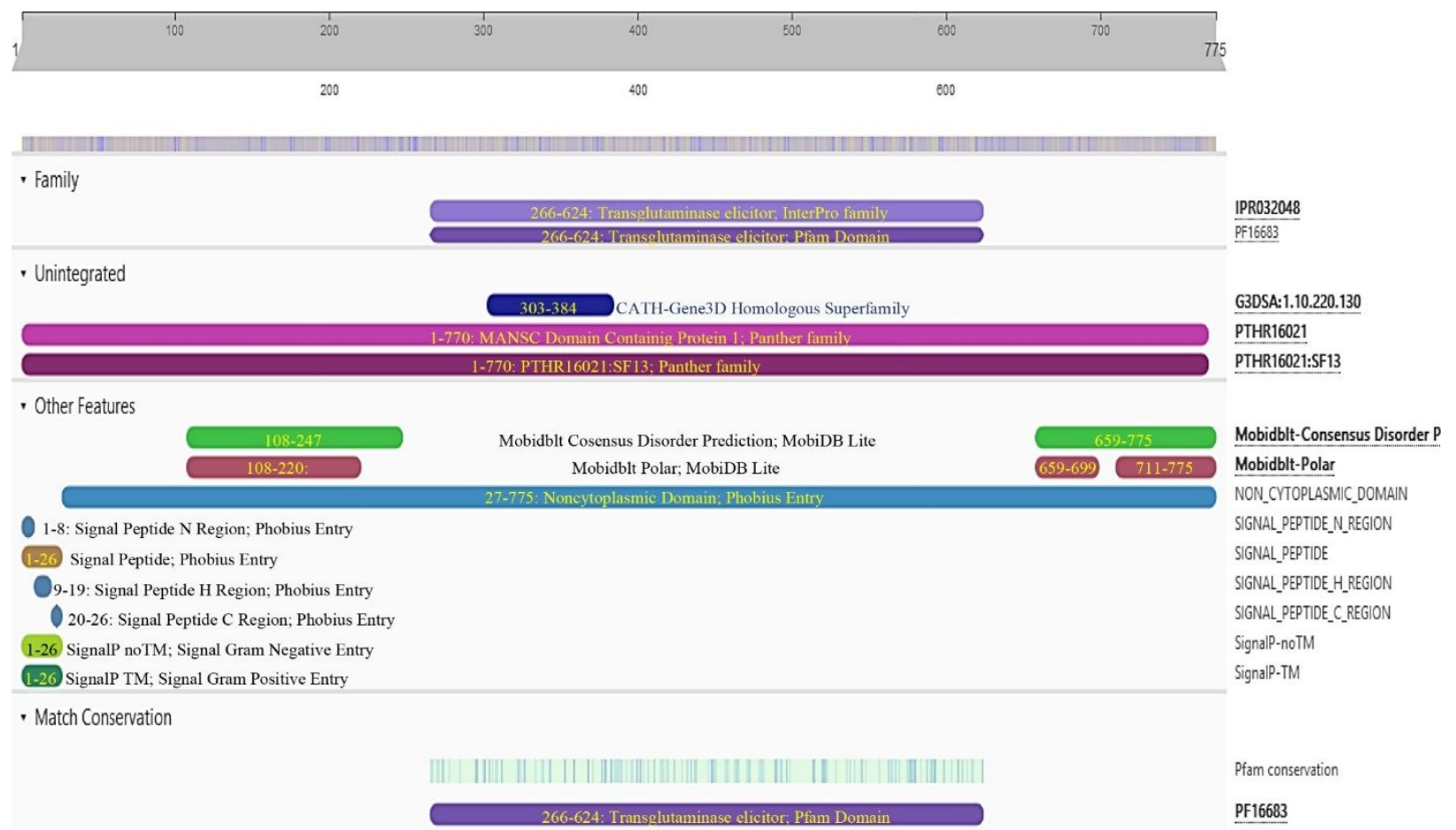

Figure S2: Intra-protein domain mapping of H3GZF6. Mapping was carried out at 100\% homology, and 100\% confidence level in comparison with the data available at Ebi database UK. A functional analysis of protein sequences was performed to classify them into families. 


\section{Supplementary Data Set 1:}

Table S6: List of structurally similar proteins

A list of already reported proteins that have structural similarities with the target protein

(H3GZF6). Publically available accession numbers of all the proteins, characterization status, carrier organism, and peptide lengths have been provided.

\begin{tabular}{|c|c|c|c|c|}
\hline S. No. & Accession & Name & Organism & Length \\
\hline 1 & A0A024FZQ2 & Uncharacterized protein & Albugo candida & 472 \\
\hline 2 & A0A024G1K6 & Uncharacterized protein & Albugo candida & 441 \\
\hline 3 & A0A024G1T6 & Uncharacterized protein & Albugo candida & 406 \\
\hline 4 & A0A024G6Q7 & Uncharacterized protein & Albugo candida & 469 \\
\hline 5 & A0A059WK16 & Uncharacterized protein & uncultured bacterium & 156 \\
\hline 6 & A0A059XE71 & Uncharacterized protein & uncultured bacterium & 302 \\
\hline 7 & A0A075ASQ8 & Uncharacterized protein & Rozella allomycis (strain CSF55) & 428 \\
\hline 8 & A0A080ZOF7 & Uncharacterized protein & Phytophthora parasitica P1976 & 441 \\
\hline 9 & $\mathrm{AOA080ZOH7}$ & Uncharacterized protein & Phytophthora parasitica P1976 & 154 \\
\hline 10 & AOA080Z0Z4 & Uncharacterized protein & Phytophthora parasitica P1976 & 438 \\
\hline 11 & A0A080Z116 & Uncharacterized protein & Phytophthora parasitica P1976 & 462 \\
\hline 12 & A0A080Z126 & Uncharacterized protein & Phytophthora parasitica P1976 & 438 \\
\hline 13 & A0A080Z127 & Uncharacterized protein & Phytophthora parasitica P1976 & 362 \\
\hline 14 & A0A080ZGU6 & Uncharacterized protein & Phytophthora parasitica P1976 & 108 \\
\hline 15 & A0A080ZGV7 & Uncharacterized protein & Phytophthora parasitica P1976 & 211 \\
\hline 16 & A0A080ZGW5 & Uncharacterized protein & Phytophthora parasitica P1976 & 910 \\
\hline 17 & A0A080ZGW7 & Uncharacterized protein & Phytophthora parasitica P1976 & 763 \\
\hline 18 & A0A080ZGW9 & Uncharacterized protein & Phytophthora parasitica P1976 & 577 \\
\hline 19 & A0A080ZGX0 & Uncharacterized protein & Phytophthora parasitica P1976 & 530 \\
\hline 20 & A0A080ZGX1 & Uncharacterized protein & Phytophthora parasitica P1976 & 297 \\
\hline 21 & A0A081A312 & Uncharacterized protein & Phytophthora parasitica P1976 & 507 \\
\hline 22 & A0A081AA89 & Uncharacterized protein & Phytophthora parasitica P1976 & 581 \\
\hline 23 & A0A081ADX9 & Uncharacterized protein & Phytophthora parasitica P1976 & 654 \\
\hline 24 & A0A081ADY9 & Uncharacterized protein & Phytophthora parasitica P1976 & 457 \\
\hline 25 & A0A081ADZ0 & Uncharacterized protein & Phytophthora parasitica P1976 & 529 \\
\hline 26 & A0A081B377 & Uncharacterized protein & Phytophthora parasitica P1976 & 461 \\
\hline 27 & A0A081B3B0 & Uncharacterized protein & Phytophthora parasitica P1976 & 312 \\
\hline 28 & AOAOLOHJE9 & Uncharacterized protein & Spizellomyces punctatus (strain DAOM BR117) & 477 \\
\hline 29 & A0A0P1A5Z1 & Uncharacterized protein & Plasmopara halstedii (Downy mildew of sunflower) & 362 \\
\hline 30 & A0A0P1A6Z8 & Transglutaminase elicitor $\mathrm{m} 81 \mathrm{~d}$ & Plasmopara halstedii (Downy mildew of sunflower) & 810 \\
\hline 31 & A0A0P1A7S7 & Uncharacterized protein & Plasmopara halstedii (Downy mildew of sunflower) & 127 \\
\hline
\end{tabular}




\section{Supplementary Data Set 1:}

\begin{tabular}{|c|c|c|c|c|}
\hline 32 & A0AOP1AI78 & Uncharacterized protein & Plasmopara halstedii (Downy mildew of sunflower) & 380 \\
\hline 33 & A0A0P1ALV8 & Uncharacterized protein & Plasmopara halstedii (Downy mildew of sunflower) & 386 \\
\hline 34 & A0A0P1AR98 & Uncharacterized protein & Plasmopara halstedii (Downy mildew of sunflower) & 443 \\
\hline 35 & AOAOP1ASE2 & Uncharacterized protein & Plasmopara halstedii (Downy mildew of sunflower) & 194 \\
\hline 36 & A0A0P1ATF3 & RxLR-like protein & Plasmopara halstedii (Downy mildew of sunflower) & 401 \\
\hline 37 & A0A0P1AW95 & RxLR-like protein & Plasmopara halstedii (Downy mildew of sunflower) & 141 \\
\hline 38 & A0A0P1AXE7 & Transglutaminase elicitor $\mathrm{m} 81 \mathrm{c}$ & Plasmopara halstedii (Downy mildew of sunflower) & 656 \\
\hline 39 & AOAOP1AZC4 & Uncharacterized protein & Plasmopara halstedii (Downy mildew of sunflower) & 132 \\
\hline 40 & AOAOP1B0I6 & RxLR-like protein & Plasmopara halstedii (Downy mildew of sunflower) & 181 \\
\hline 41 & A0A0P1B0K6 & RxLR-like protein & Plasmopara halstedii (Downy mildew of sunflower) & 393 \\
\hline 42 & A0A0S6W9F1 & Uncharacterized protein & Candidatus Vecturithrix granuli & 422 \\
\hline 43 & A0A0W8B0J1 & Uncharacterized protein & Phytophthora nicotianae (Buckeye rot agent) & 154 \\
\hline 44 & A0A0W8BYF3 & Transglutaminase elicitor M81C & Phytophthora nicotianae (Buckeye rot agent) & 575 \\
\hline 45 & A0AOW8BZ72 & $A B C$ transporter $\mathrm{G}$ family member 10 & Phytophthora nicotianae (Buckeye rot agent) & 530 \\
\hline 46 & A0A0W8C021 & Uncharacterized protein & Phytophthora nicotianae (Buckeye rot agent) & 768 \\
\hline 47 & A0A0W8C028 & Uncharacterized protein & Phytophthora nicotianae (Buckeye rot agent) & 910 \\
\hline 48 & A0A0W8C034 & Transglutaminase elicitor protein & Phytophthora nicotianae (Buckeye rot agent) & 577 \\
\hline 49 & AOAOW8C2EO & Elicitor transglutaminase M81B & Phytophthora nicotianae (Buckeye rot agent) & 454 \\
\hline 50 & AOAOW8C2P4 & Transglutaminase elicitor M81D & Phytophthora nicotianae (Buckeye rot agent) & 530 \\
\hline 51 & A0A0W8C5I9 & Uncharacterized protein & Phytophthora nicotianae (Buckeye rot agent) & 295 \\
\hline 52 & A0A0W8C5L3 & Uncharacterized protein & Phytophthora nicotianae (Buckeye rot agent) & 182 \\
\hline 53 & A0A0W8C9Y4 & Uncharacterized protein & Phytophthora nicotianae (Buckeye rot agent) & 450 \\
\hline 54 & A0A0W8CAE1 & Uncharacterized protein & Phytophthora nicotianae (Buckeye rot agent) & 477 \\
\hline 55 & A0A0W8CJR5 & Transglutaminase elicitor M81C & Phytophthora nicotianae (Buckeye rot agent) & 280 \\
\hline 56 & A0A0W8CKA4 & Transglutaminase elicitor M81C & Phytophthora nicotianae (Buckeye rot agent) & 709 \\
\hline 57 & AOAOW8CNG0 & Transglutaminase elicitor M81C & Phytophthora nicotianae (Buckeye rot agent) & 723 \\
\hline 58 & A0A0W8CQ88 & Alpha-tubulin $\mathrm{N}$-acetyltransferase & Phytophthora nicotianae (Buckeye rot agent) & 557 \\
\hline 59 & A0A0W8CQE8 & HIV Tat-specific factor 1 & Phytophthora nicotianae (Buckeye rot agent) & 598 \\
\hline 60 & A0A0W8CQY5 & Uncharacterized protein & Phytophthora nicotianae (Buckeye rot agent) & 507 \\
\hline 61 & AOAOW8CRG0 & Cell 12A endoglucanase & Phytophthora nicotianae (Buckeye rot agent) & 654 \\
\hline 62 & A0A0W8CVC5 & Elicitor transglutaminase M81 protein & Phytophthora nicotianae (Buckeye rot agent) & 613 \\
\hline 63 & AOAOW8CYN8 & Uncharacterized protein & Phytophthora nicotianae (Buckeye rot agent) & 450 \\
\hline 64 & A0A0W8D2P1 & Uncharacterized protein & Phytophthora nicotianae (Buckeye rot agent) & 362 \\
\hline 65 & A0A0W8D4D5 & Uncharacterized protein & Phytophthora nicotianae (Buckeye rot agent) & 215 \\
\hline 66 & A0A0W8D6J8 & Protocadherin Fat 4 & Phytophthora nicotianae (Buckeye rot agent) & 438 \\
\hline 67 & A0AOW8DDY0 & $A B C$ transporter $\mathrm{G}$ family member 31 & Phytophthora nicotianae (Buckeye rot agent) & 891 \\
\hline 68 & A0A0W8DIP9 & Uncharacterized protein & Phytophthora nicotianae (Buckeye rot agent) & 289 \\
\hline 69 & A0A0W8DJU1 & BZIP transcription factor 1 & Phytophthora nicotianae (Buckeye rot agent) & 438 \\
\hline 70 & A0A0W8DKG4 & Inorganic phosphate transporter family & Phytophthora nicotianae (Buckeye rot agent) & 438 \\
\hline 71 & A0A0W8DYJ1 & Uncharacterized protein & Phytophthora nicotianae (Buckeye rot agent) & 356 \\
\hline 72 & A0A0W8DZ44 & Uncharacterized protein & Phytophthora nicotianae (Buckeye rot agent) & 452 \\
\hline
\end{tabular}




\section{Supplementary Data Set 1:}

\begin{tabular}{|c|c|c|c|c|}
\hline 73 & AOAOW8E0CO & 3-hydroxyisobutyrate dehydrogenase & Phytophthora nicotianae (Buckeye rot agent) & 507 \\
\hline 74 & A0A150NZI5 & Uncharacterized protein & Sorangium cellulosum & 512 \\
\hline 75 & A0A150PCB8 & Uncharacterized protein & Sorangium cellulosum & 512 \\
\hline 76 & A0A150PDI7 & Uncharacterized protein & Sorangium cellulosum & 507 \\
\hline 77 & A0A150QD88 & Uncharacterized protein & Sorangium cellulosum & 510 \\
\hline 78 & A0A150QLK5 & Uncharacterized protein & Sorangium cellulosum & 504 \\
\hline 79 & A0A150QRV6 & Uncharacterized protein & Sorangium cellulosum & 512 \\
\hline 80 & A0A150R3Y6 & Uncharacterized protein & Sorangium cellulosum & 512 \\
\hline 81 & A0A150R4Q6 & Uncharacterized protein & Sorangium cellulosum & 512 \\
\hline 82 & A0A150RBZ5 & Uncharacterized protein & Sorangium cellulosum & 512 \\
\hline 83 & A0A150RTW4 & Uncharacterized protein & Sorangium cellulosum & 512 \\
\hline 84 & A0A150SG90 & Uncharacterized protein & Sorangium cellulosum & 510 \\
\hline 85 & A0A150TH55 & Uncharacterized protein & Sorangium cellulosum & 335 \\
\hline 86 & A0A150TII9 & Uncharacterized protein & Sorangium cellulosum & 512 \\
\hline 87 & A0A150WD98 & Uncharacterized protein & Bdellovibrio bacteriovorus & 386 \\
\hline 88 & A0A1F3SQ79 & Uncharacterized protein & Bdellovibrionales bacterium GWA2_49_15 & 509 \\
\hline 89 & A0A1F3SXK5 & Uncharacterized protein & Bdellovibrionales bacterium RBG_16_40_8 & 498 \\
\hline 90 & A0A1F3SYA4 & Uncharacterized protein & Bdellovibrionales bacterium GWB1_55_8 & 526 \\
\hline 91 & A0A1F3SZI9 & Uncharacterized protein & Bdellovibrionales bacterium GWB1_55_8 & 328 \\
\hline 92 & A0A1F3T1Z2 & Uncharacterized protein & Bdellovibrionales bacterium GWB1_55_8 & 464 \\
\hline 93 & A0A1F3TA26 & Uncharacterized protein & Bdellovibrionales bacterium RIFOXYA1_FULL_36_14 & 324 \\
\hline 94 & A0A1F3TA35 & Uncharacterized protein & Bdellovibrionales bacterium RIFOXYA1_FULL_36_14 & 484 \\
\hline 95 & A0A1F3TSY1 & Uncharacterized protein & Bdellovibrionales bacterium RIFCSPHIGHO2_01_FULL_40_29 & 421 \\
\hline 96 & A0A1F3TVY2 & Uncharacterized protein & Bdellovibrionales bacterium RIFCSPHIGHO2_01_FULL_40_29 & 466 \\
\hline 97 & A0A1F3TYK4 & Uncharacterized protein & Bdellovibrionales bacterium RIFCSPHIGHO2_01_FULL_40_29 & 483 \\
\hline 98 & A0A1F3VBL8 & Uncharacterized protein & Bdellovibrionales bacterium RIFOXYC1_FULL_39_130 & 406 \\
\hline 99 & A0A1F3VBR0 & Uncharacterized protein & Bdellovibrionales bacterium RIFOXYC1_FULL_37_79 & 324 \\
\hline 100 & A0A1F3VLF9 & Uncharacterized protein & Bdellovibrionales bacterium RIFOXYC1_FULL_37_79 & 531 \\
\hline
\end{tabular}




\section{Supplementary Data Set 1:}

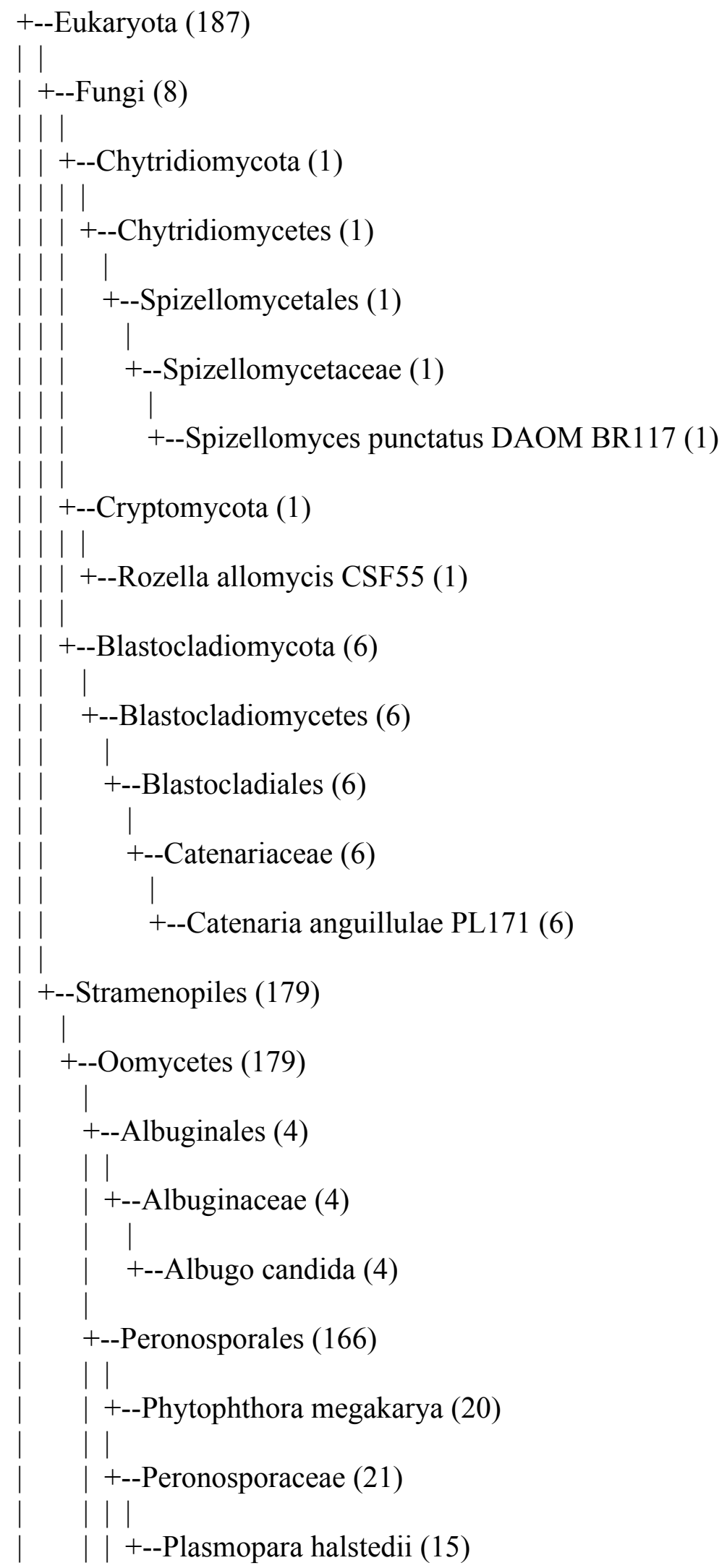




\section{Supplementary Data Set 1:}

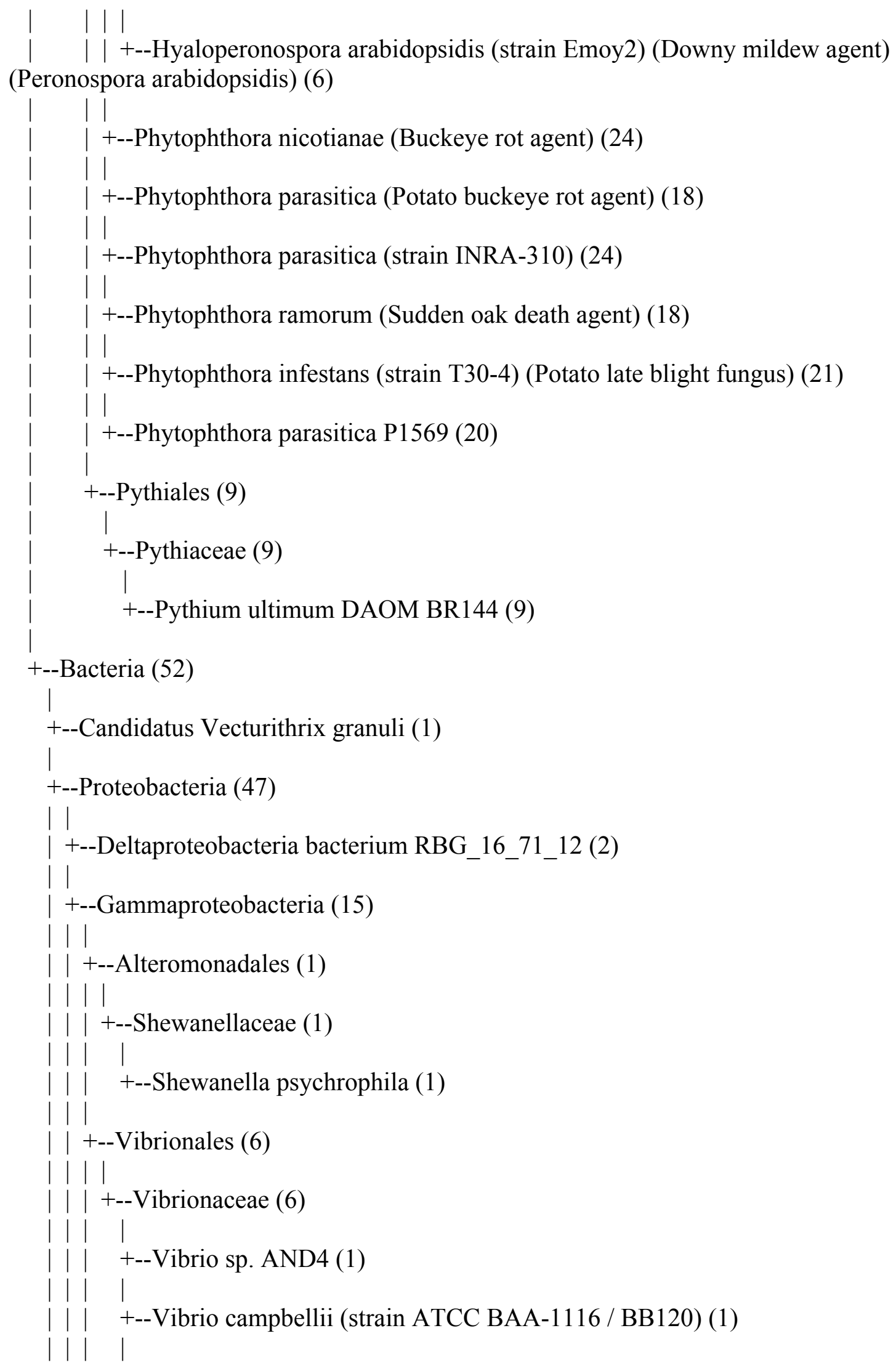




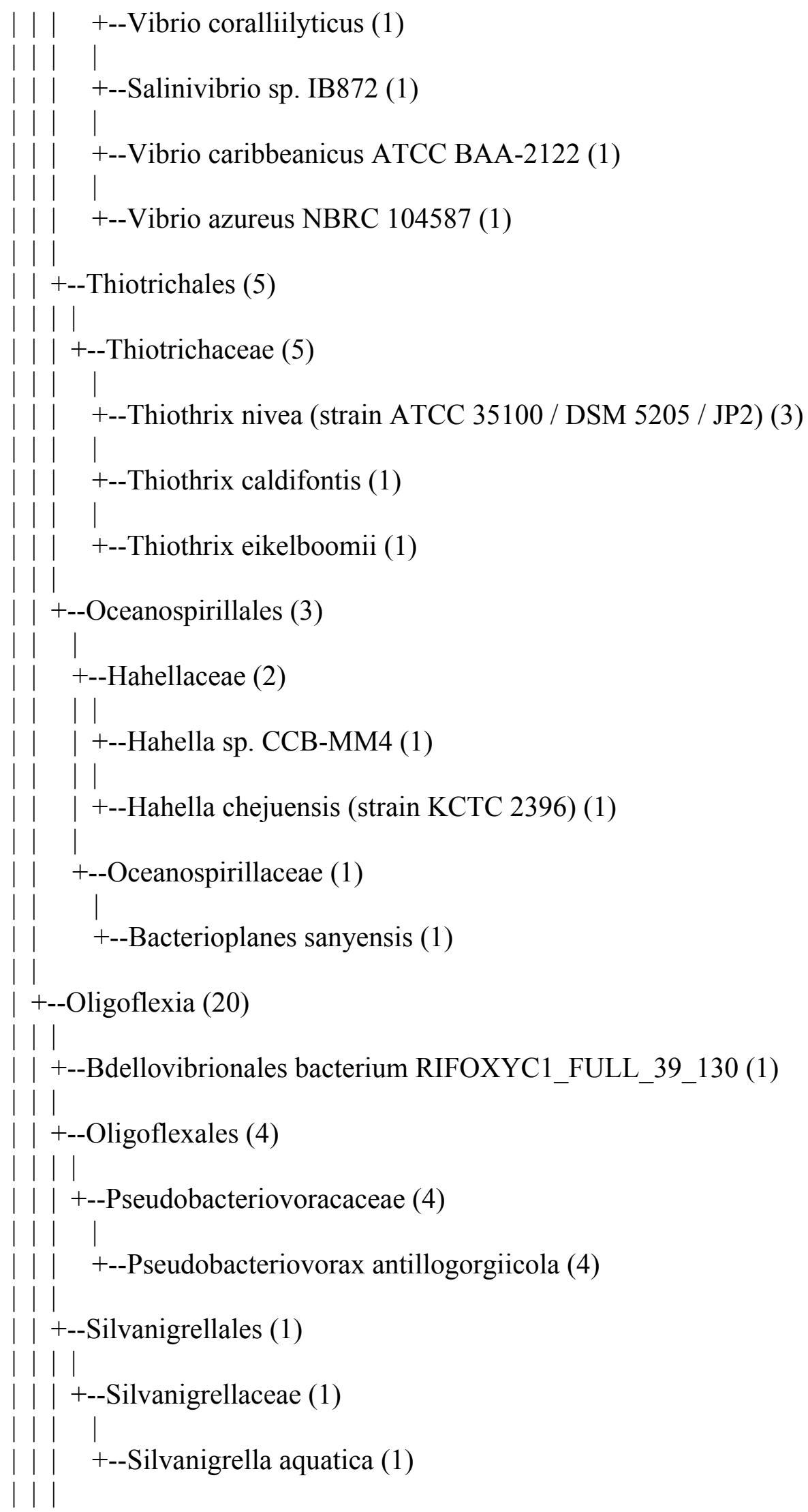




\section{Supplementary Data Set 1:}

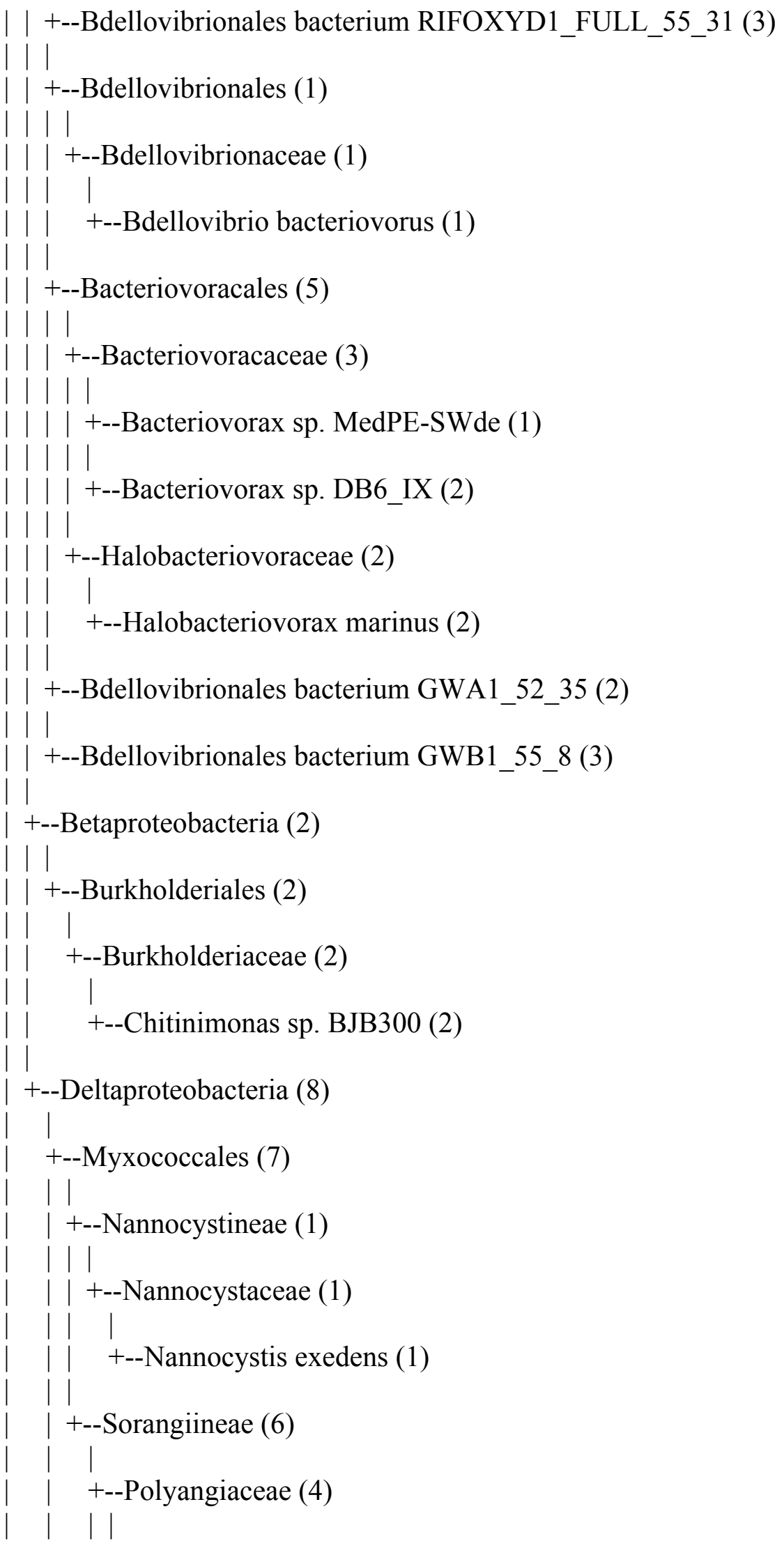




\section{Supplementary Data Set 1:}

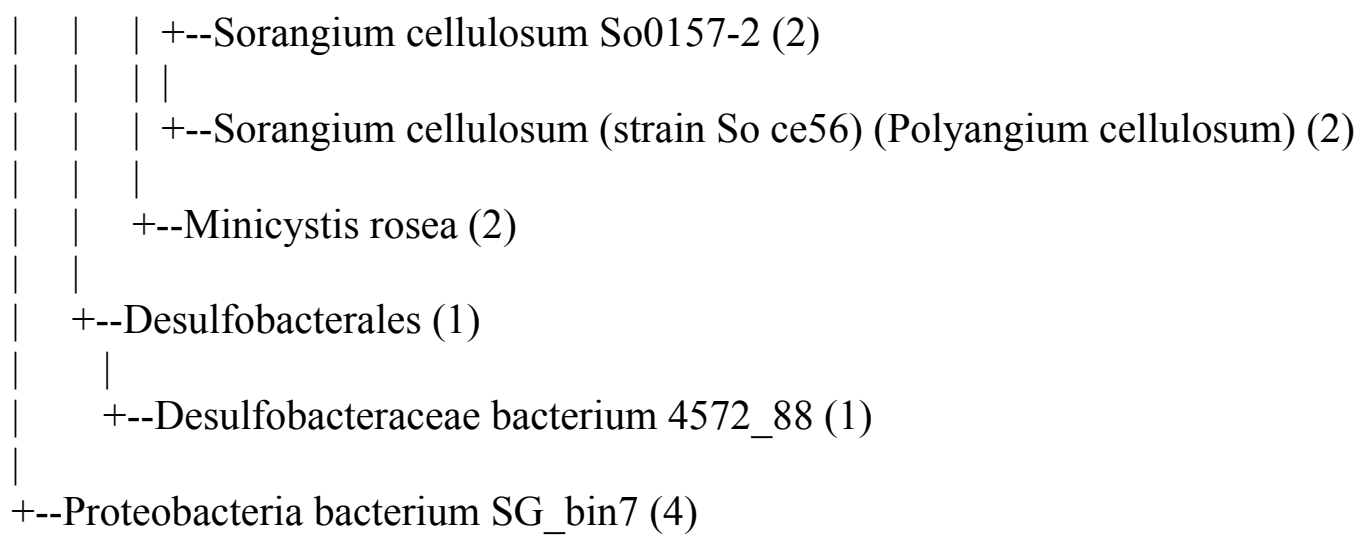

Figure S3: A dendrogram showing the occurrence of the protein in different organisms, along with the taxonomic positions of the organisms bearing the protein. 


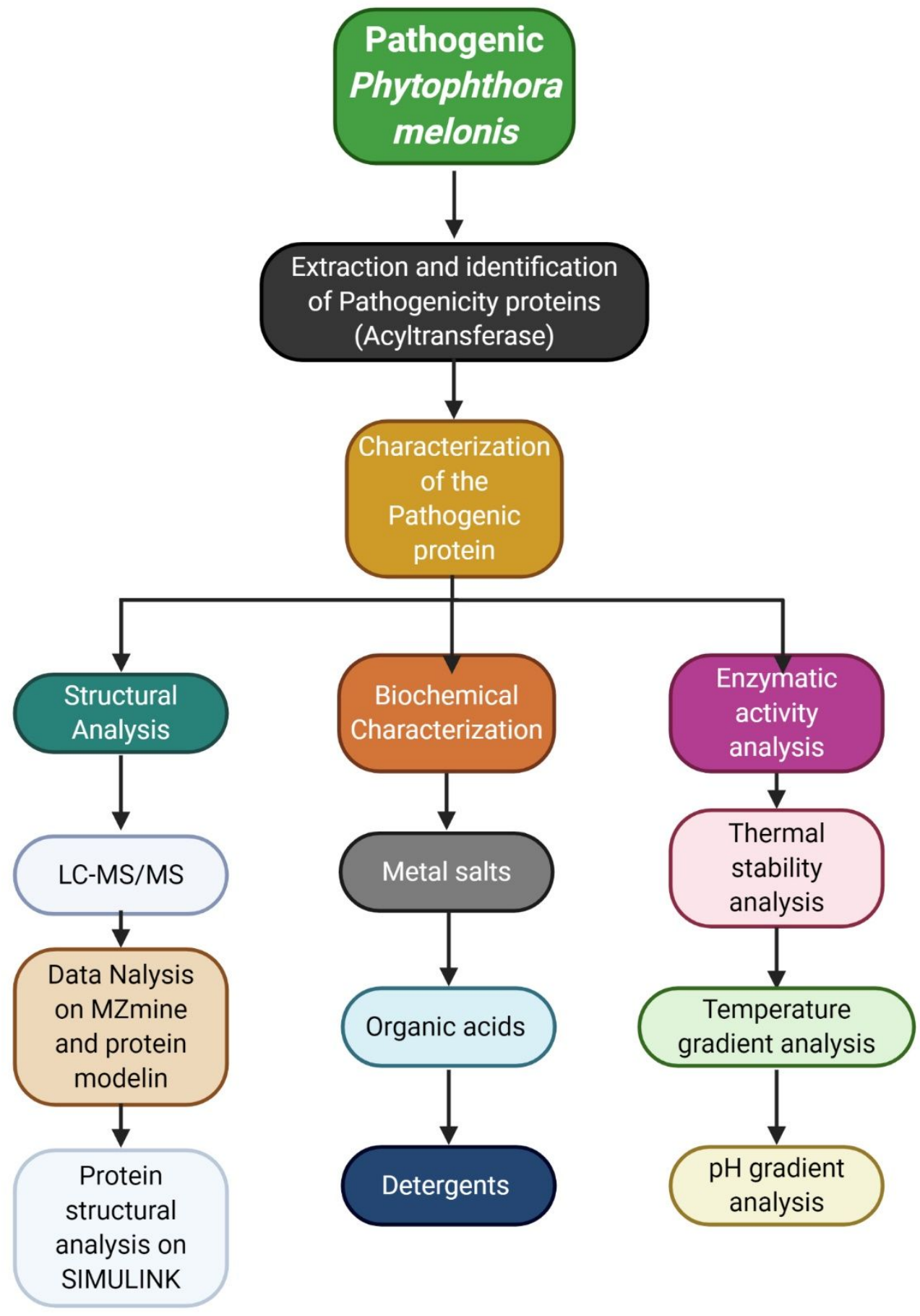

Figure S4: Flow chart diagram of the study. 